\title{
JURISPRUDENCIA SOBRE EL ERROR EN LA PERSONA Y VICIO DEL CONSENTIMIENTO MATRIMONIAL DURANTE LA VIGENCIA DE LA “LEY DE MATRIMONIO CIVIL” DE 1884
}

[Jurisprudence Oferrors Concerning the Person and Defect in Marital Consent During the Validity of the "Civil Marriage Act" of 1884]

\author{
Alexis Mondaca Miranda* \\ Universidad Católica del Norte, Antofagasta, Chile
}

\begin{abstract}
RESUMEN
El artículo estudia los tipos de errores en la persona comprendidos en el $\mathrm{N}^{\circ} 1 \mathrm{del}$ artículo 33 de la Ley de matrimonio civil de 1884. Luego de una breve referencia al estado de la cuestión en la doctrina, se analiza la jurisprudencia chilena relativa al precepto recientemente enunciado. Finalmente, se señala nuestra opinión sobre lo resuelto en los fallos que se analizan y los fundamentos de éstos.
\end{abstract}

Palabras Clave

Error en la persona - Nulidad matrimonial - Vicios del consentimiento.

\begin{abstract}
This article studies the type of errors concerning the person stipulated in Article 33 No. 1 of the Civil Marriage Act of 1884 . After a brief reference to the current status of the doctrine, the Chilean jurisprudence regarding the aforementioned concept is analysed. Finally, we put forward our opinion as to the resolutions handed down which are under analysis and their grounds.
\end{abstract}

\section{KEYWORDS}

Error concerning the person - Marriage annulment - Defect in consent.

ReCiBIDo el 16 de julio y ACEPTADo el 22 de diciembre de 2014

* Profesor de derecho civil de la Escuela de Derecho de la Facultad de Ciencias Jurídicas de la Universidad Católica del Norte, Antofagasta. Dirección postal: Avenida Angamos 0610, Antofagasta, Chile. Correo electrónico: amondaca@ucn.cl. Este artículo es una adaptación de uno de los capítulos de nuestra tesis doctoral titulada " $E l$ error en las cualidades en el derecho matrimonial del Estado de Chile", defendida por el autor el 17 de diciembre de 2012 en la Pontificia Universidad Católica de Valparaíso. 


\section{INTRODUCCIÓN}

El 10 de enero de 1884 se promulgó la primera disciplina laica matrimonial que rigió en nuestro país, la que entró en vigencia el 1 de enero de 1885. Ella vino a reemplazar la hasta entonces normativa canónica que era aplicable en materia civil, en conformidad con lo dispuesto en el inciso $2^{\circ}$ del artículo 103 y el artículo 118, ambos del Código Civil'. La Ley de matrimonio civil de 1884, a propósito de las causales de nulidad, reguló los supuestos de falta de un libre y espontáneo consentimiento matrimonial en el artículo 33. En el $\mathrm{N}^{\circ} 1$ de la referida norma se sancionaba el error en la identidad del otro cónyuge, en el $\mathrm{N}^{\circ} 2$, el vicio de fuerza en los términos de los artículos 1456 y 1457 CC., y en el $\mathrm{N}^{\circ} 3$, el rapto de la mujer, siempre que ésta, a la época del matrimonio, no hubiese recuperado su libertad. Como acabamos de señalar, el yerro en la identidad física se sancionaba en el $\mathrm{N}^{\circ} 1$ del artículo 33 en los términos que siguen: "Falta el consentimiento libre y espontáneo en los casos siguientes: 1 . Si ha habido error en cuanto a la identidad de la persona del otro contrayente".

La fuente de la transcrita norma fue el derecho canónico. No obstante tratarse de una regulación laica, producida en el complejo proceso de separación de Iglesia-Estado, el error en la identidad de la persona, al igual que la ley toda, es una traducción en clave laica de la disciplina canónica matrimonial. Así lo ha señalado Salinas ${ }^{2}$. A la época de entrada en vigencia de la Ley de matrimonio civil de 1884, en sede canónica, los errores en la persona con poder dirimente del consentimiento matrimonial eran: el error en la identidad física, el error en la condición de esclavo; el error redundans (la cualidad identificaba de tal forma al otro contrayente que redundaba en la identidad de éste ${ }^{3}$ ); y el error en cualidad directamente intentada.

${ }^{1}$ Salinas Araneda, Carlos, El influjo del derecho canónico en el Código Civil de la República de Chile (Valparaíso, Ediciones Universitarias de Valparaíso, 2006), pp. 93-104.

${ }^{2}$ Salinas Araneda, Carlos, El error en el matrimonio (Santiago de Chile, Universidad Central de Chile, 2005), II, p. 501.

${ }^{3}$ Para Tomás Sánchez, el error redundans era una subespecie de error in persona. Sostuvo que debía limitarse el error en cualidad redundante, en el sentido de exigir una cualidad que designaba a una persona específica, excluyéndose, de este modo, el supuesto de una cualidad común a varias personas, como el hecho de ser médico o militar. Siempre según Tomás Sánchez, deben reunirse tres requisitos para que el error en cualidad se convierta en error redundante, en primer lugar, que el error recaiga sobre una cualidad que sea propia y exclusiva que identifique al otro contrayente (lo que no era exigido por Santo Tomás), en segundo término, que esa persona no sea directamente conocida por el que sufre el error y, tercero, "que no conste que la intención del contrayente es la de casarse con la persona que se le presente, sea ésta quien fuere”, SáNCHEZ, 
Si bien es cierto que, algunos de los primeros comentaristas, como Chacón ${ }^{4}$, se limitaban a enunciar, en términos generales, el vicio de error como un impedimento de fondo, buena parte de la doctrina nacional discutía qué tipos de error en la persona debían entenderse comprendidos en la fórmula legal que empleaba la norma en comento. Existía consenso en que se sancionaba el error en la identidad física del otro contrayente, es decir, aquel yerro que recae en la corporeidad del otro. La duda radicaba sobre si, además, se incluía el yerro en la identidad social y el error en las cualidades. Se entendía por error en la identidad social de la persona, también denominado error en la identidad civil, siguiendo a Claro Solar ${ }^{5}$, el yerro sobre "las condiciones que determinan el lugar permanente que debe ocupar en la sociedad". Por su parte, el error en las cualidades, en términos de Saavedra ${ }^{6}$, dice relación con las cualidades personales que, según la naturaleza del negocio, suelen ser tomados en consideración como relevantes para la formación de la voluntad del declarante.

En este contexto, tres eran las posiciones que adoptaba la doctrina de la época: una primera, que calificamos de restringida, sostenía que en el $\mathrm{N}^{\circ} 1$ del artículo 33 únicamente se sancionaba el error en la identidad física, y no las otras clases de error en la persona. Un segundo sector de la doctrina afirmaba que la norma se refería, además, al yerro en la identidad social. Finalmente, una última posición, amplia, opinaba que el legislador establecía la nulidad para el error en la identidad corporal, el error en la identidad civil y el error en las cualidades.

Con respecto a la jurisprudencia, y a diferencia de lo que sucedió con la doctrina, como señalaremos prontamente con mayor detalle, existió unani-

Tomás, Disputationum de sancto matrimonii sacramento, lib. VII, disp. 18 (Antuerpiae, 1626), II, pp. 64-69. Esta concepción más restringida del error redundans fue recepcionada por la mayoría de la doctrina y jurisprudencia. Siguiendo a San Alfonso $\mathrm{M}^{\mathrm{A}} \mathrm{de}$ Ligorio, si la cualidad no es común a otros, sino que propia e individual de una determinada persona, como si alguien pretendiese casarse con la primogénita del rey de España, entonces, si se yerra en la cualidad se ha errado en la persona, por lo que el matrimonio es nulo. Se aprecia en esta regla la recepción por parte de San Alfonso de las ideas de Tomás Sánchez, Alfonso M ${ }^{\mathrm{A}}$ DE Ligorio, San, Theologia moralis (2a edición, Neapoli, 1755), lib. V (VI), tract, de matr., cap. $3^{\circ}$, dub, 2, pp. 523-525, n. 1015. Véase, además: RuAno Espina, Lourdes, El error de cualidad, como causal de nulidad matrimonial, en los ordenamientos canónico y civil, en Revista de Derecho Privado, 76 (1992), p. 10

${ }^{4}$ Chacón, Jacinto, Esposicion razonada y estudio comparado del Código Civil chileno (Valparaíso, Imprenta del Mercurio, 1868), pp. 93-94.

${ }^{5}$ Claro Solar, Luis, Explicaciones de derecho civil chilenoy comparado (2a edición, Santiago de Chile, Editorial Jurídica de Chile, 1992), I,1, p. 296.

${ }^{6}$ SaAvedra, Francisco, Teoría del consentimiento (Santiago de Chile, Editorial Jurídica ConoSur, 1994), p. 209. 
midad en restringir el contenido del $\mathrm{N}^{\circ} 1$ del artículo 33 exclusivamente al error en la identidad física del otro contrayente, descartando, a propósito del matrimonio, la relevancia dirimente de las otras especies de error en la persona. Antes de continuar, hacemos presente que el análisis de la historia fidedigna del artículo 33, en este caso, no nos proporciona antecedente alguno de relevancia para la presente investigación, ya que, en la Cámara de Diputados, el proyecto fue aprobado sin debate y sin que se efectuaran modificaciones, salvo por un pequeño cambio: en el proyecto presentado a la Cámara de Diputados, la norma que regulaba la falta de un libre y espontáneo consentimiento tenía asignada el $\mathrm{N}^{\circ} 48^{7}$. Durante su tramitación en la misma Cámara se le otorgó su $\mathrm{N}^{\circ}$ definitivo. En diciembre de 1883 pasó el proyecto al Senado, ninguna indicación ni modificación fue efectuada en el Senado ${ }^{8}$.

\section{Doctrina Relativa A LAS ESPECIES DE ERROR EN LA PERSONA COMPRENDIDOS EN EL $\mathrm{N}^{\circ} 1$ DEL ARTí́CULO 33}

La relevancia de la discusión referida radicaba en que, según se optase por el criterio restringido, intermedio o amplio, se determinaba el campo de aplicación de la norma. Así, si se sostenía que solo tenía efecto dirimente del consentimiento matrimonial el error en la identidad física, el precepto, prácticamente, devenía en inaplicable, puesto que, podemos entender que tal especie de error es de difícil, aunque no imposible, producción. Por otro lado, de optarse por el criterio amplio, aumentaban las posibilidades de aplicación del error en el matrimonio al no limitarse éste exclusivamente al yerro de más improbable ocurrencia. A continuación analizaremos, brevemente, esta discusión para con posterioridad referirnos a los correspondientes pronunciamientos jurisprudenciales.

\section{Doctrina restringida.}

En conformidad a esta doctrina, el único error que atentaba en contra del libre y espontáneo consentimiento matrimonial era el que versaba sobre la identidad del otro contrayente físicamente considerado. Así, para Barros, el error en la persona se limitaba al error en la identidad de la misma, y no debía extenderse al error en sus cualidades, aunque éstas fuesen esenciales. Justificaba su posición con el argumento de evitar perturbaciones graves para

${ }^{7}$ En efecto, el artículo 48 fue aprobado sin debate: TAPIA DE LA TORRE, José, Discusión parlamentaria de la Ley de matrimonio civil chilena (memoria de grado, Pontificia Universidad Católica de Valparaíso, Valparaíso, 1990), pp. 146-188.

${ }^{8}$ Pinochet Elorza, César, El error en la persona en el contrato de matrimonio (memoria de grado, Universidad de Chile, Santiago de Chile, 1960), p. 32. 
la sociedad ${ }^{9}$. En similar sentido, Alessandri, para quien sólo correspondía aceptar el error en la identidad física y debía excluirse el error en las cualidades, no pronunciándose sobre el error en la identidad social, aunque nos parece que opta por la negativa; si bien es cierto que, no lo afirmó en términos explícitos, ello puede colegirse de sus palabras al afirmar: "El único error que en esta materia se acepta es el que recae sobre la identidad de la persona del otro contratante [...] Hay error en la identidad de la persona cuando se yerra en la persona física". Interesante resulta ser la justificación de Alessandri para descartar la procedencia del error en las cualidades, puesto que lo consideraba un error en los motivos, el que es tradicionalmente irrelevante, no obstante lo importante que puedan ser las cualidades sobre las que se ha errado ${ }^{10}$.

Rozas y Barros, después de hacer presente que para algunos autores y para la jurisprudencia el error en la persona se limitaba al error en la identidad física, agregaban que la doctrina estaba conteste en excluir como causal de nulidad el error en las cualidades ${ }^{11}$.En el mismo sentido se pronunció Rossel, quien luego de afirmar que, en materia matrimonial el concepto de error es diferente al que existe en sede patrimonial, se manifestaba en contra de aceptar el error en la persona social y por extensión, el error en las cualidades. El problema surgía, según Rossel, al tratar de determinar cuáles de dichas cualidades constituían la persona civil: "el aceptar que el error en la persona civil es vicio del consentimiento, nos lleva por un plano inclinado a aceptar que el error sobre determinadas cualidades o atributos morales sería causal suficiente de nulidad, lo que es a todas luces peligroso e inconveniente". Para seguir fundando su opinión, Rossel recurrió a la diferencia existente en la disciplina del error matrimonial entre Chile y Francia. El legislador nacional empleaba la frase, en el artículo $33 \mathrm{~N}^{\circ} 1$ de la Ley de matrimonio civil, "identidad de la persona", mientras que el artículo 180 CCFr., usaba la fórmula "error en la persona". Esta diversidad lo llevó a concluir que nuestro legislador innovó respecto del Código francés, ya que la norma chilena era más específica, puesto que la referencia a la "identidad de la persona" implicaba, en forma inequívoca, el ser físico, excluyendo el conjunto de calidades comprendidas en la noción de "persona civil o social", concepto que en su opinión es "puramente intelectual y simbólico".

Sin perjuicio de manifestarse en contra de la admisión de otro error en

${ }^{9}$ Barros Errázuriz, Alfredo, Curso de derecho civil. Tercer año (3a edición, Santiago de Chile, Imprenta Cervantes, 1921), p. 36.

${ }^{10}$ Alessandri Rodríguez, Arturo, derecho Civil. Tercer Año. derecho de Familia. De la sucesión por causa de muerte (Santiago de Chile, Editor: Pedro Trouvé, 1932), pp. 13-14.

${ }^{11}$ Rozas Vial, Fernando - Barros Freire, Jorge, Derecho civil. Derecho de familia (Santiago de Chile, Ediciones Albatros Chilena, 1970), I, p. 41. 
la persona diverso al yerro en la identidad física, en razón de la legislación comparada que había regulado el error en las cualidades, Rossel manifestaba que sería deseable que una futura reforma de la Ley de matrimonio civil considerare en forma especial este punto. Su aspiración sólo se concretó, como bien sabemos, el año $2004^{12}$.

\section{Doctrina intermedia.}

La segunda posición amplía el campo de aplicación del $\mathrm{N}^{\circ} 1$ del artículo 33, dado que, además del yerro en la identidad física, entendía sancionado el error en la identidad civil. Partidario de esta interpretación fue Fueyo ${ }^{13}$, quien consideraba que el error sobre la persona civil podía servir para fundar una declaración de nulidad, pero lo restringía al supuesto de usurpación de identidad. Razonaba sobre la base de una usurpación de documentos de identificación personal, de modo que, valiéndose de ellos se falsease los atributos civiles del afectado y se lo suplantase. En esta situación, el impostor podría engañar al Oficial del Registro Civil, el que casaría a una persona que ignoraba lo sucedido, mientras que el autor de la usurpación, no había contraído matrimonio. Pero Fueyo no fue partidario de incluir como vicio de la voluntad el error en las cualidades". Afirmó que lo que escape del error en la persona física y en la identidad civil entra en el terreno de intereses frustrados: "en lo cual se podría comprender infinidad de otras cualidades, como fortuna, energías de toda especie, influencias, etc., lo que parece inaceptable porque sería llevar el matrimonio al campo de un materialismo inconveniente y repugnante, con base en el interés puro". Fueyo temía que de admitirse el error en las cualidades se pudiesen deducir acciones carentes de seriedad ${ }^{14}$.

Sostuvo Claro Solar ${ }^{15}$, como todos, que el error en la identidad física irritaba el consentimiento matrimonial: "Por ejemplo, yo quiero casarme con María y por un concurso de circunstancias extraordinarias Julia se presenta en su lugar ante el Oficial de Registro Civil y creyendo estar al lado de María, declaro consentir en tomarla por esposa: el error no puede ser más radical". Hizo presente el autor la rarísima ocurrencia de esta hipótesis de error y acudió a la Biblia ${ }^{16}$ para ofrecer un nuevo ejemplo; el error que sufrió Jacob, el que, creyendo contraer matrimonio con Raquel, se casó con su prima Lía.

También consideraba como vicio de la voluntad el error en la persona

${ }^{12}$ Rossel SaAvedra, Enrique, Manual de derecho de familia (6a edición, Santiago de Chile, Editorial Jurídica de Chile, 1992), pp. 26-27.

${ }^{13}$ Fueyo Laneri, Fernando, Derecho civil. Derecho de familia (Santiago de Chile, Imp. y Lito. Universo S.A., 1959), VI,1, pp. 99-100.

${ }^{14}$ Ibíd., p. 100.

${ }^{15}$ Claro Solar, Luis, cit. (n. 5), p. 296.

${ }^{16}$ Gen. 29. 
civil o social ${ }^{17}$, ya que este error se relacionaba con la identidad y la noción de "persona" no debía restringirse a su identidad física, sino que comprendía a la persona civil, por ello, dicho error impedía un consentimiento libre y espontáneo. Planteó como ejemplo un supuesto de usurpación de identidad: un pariente que vive en España solicitaba a la hija de una persona para que se casase con su hijo, al que sólo se conocía de nombre. Una vez aceptada la proposición, un aventurero, empleando documentación falsa usurpaba el nombre del novio y celebraba matrimonio con la mujer. Ésta ha incurrido en un error ya que ha contraído vínculo con una persona diversa de la deseada, dado que entendía casarse con el hijo de un pariente y, en cambio, su marido no tenía ningún vínculo de parentesco con ella, configurándose, de este modo, el error en la identidad social ${ }^{18}$. En el ejemplo citado, una cualidad determinada, el parentesco, era considerada esencial para otorgar el consentimiento, ya que venía a redundar en la identidad del otro contrayente y era, precisamente, el error sobre una cualidad que se consideraba presente en el otro, en circunstancias que no lo estaba, lo que provocaba el vicio de la voluntad. Es decir, aunque no usa la terminología propia del derecho canónico, Claro Solar se refiere al error redundans.

Claro Solar, entonces, afirmaba la admisión del error en la identidad física, pero no aceptaba el error en las cualidades. Dado que afirmaba la relevancia del error en el supuesto en que los futuros cónyuges no se conocían, este error redundans viciaba la voluntad, pero seguía siendo un error en la identidad, no un error en las cualidades. Afirmaba expresamente: "La teoría que admite el error sobre la persona civil está expuesta al peligro de ser extendida a las cualidades civiles o sociales, que es lo que han hecho en Francia Marcadé y Demolombe al comentar la expresión error en la persona empleada por el artículo 180 del Código de Napoleón”19.

${ }^{17}$ Claro Solar, Luis, cit. (n. 5), p. 296.

${ }^{18}$ Ibíd.

${ }^{19}$ Ibíd., p. 297. A mayor abundamiento, Claro Solar realizó un estudio de la regulación del error sustancial del artículo 1454 CC., comparándolo con el matrimonio. En virtud de la norma aludida, el error en una cualidad de la cosa vicia la voluntad en dos casos: primero, si se trata de una cualidad esencial del objeto del acto o contrato; en segundo término, si se trata de una cualidad accidental, pero las partes la han elevado a la categoría de calidad esencial, al considerarla como el principal motivo de una de ellas para contratar, siempre que esto sea conocido por la otra parte. Pero el matrimonio es distinto del resto de los contratos, o como los denomina el autor, "contratos ordinarios", para resaltar las peculiaridades del matrimonio, agregaba que: "pero estos principios son absolutamente inaplicables al matrimonio, en el cual no puede depender de la voluntad de las partes el que tal o cual calidad llegue a ser substancial, y, por lo tanto, una condición de validez del matrimonio", de forma tal que, y considerando el interés público existente en el matrimonio, no puede admitirse que las cualidades del otro 
En el ámbito de las tesis de grado, destaca la obra de Pinochet ${ }^{20}$, sus argumentos fueron:

i) Si se restringía el $\mathrm{N}^{\circ} 1$ del artículo 33 sólo al error en la identidad física, tal norma pasaría a ser inoperante, dada la escasa posibilidad de ser aplicada.

ii) Según el artículo 23 CC., en la interpretación de la ley no deberá estarse a si ésta es favorable u odiosa, de este modo, se combatía el argumento que sostenía que de aceptarse que el $\mathrm{N}^{\circ} 1$ del artículo 33 incluyese el error en la persona social, se causarían graves perturbaciones para la sociedad en razón de la no existencia en Chile de un divorcio con disolución de vínculo.

iii) En conformidad a la definición legal de "persona" del artículo 55 CC., toda persona debe tener una edad, sexo, estirpe y condición, esto es, para el legislador la persona no se reduce al individuo en sí físicamente considerado, sino que la trata como sujeto de derechos. Del mismo modo que no puede concebirse a una persona sin edad o sexo, tampoco ello procede ante la ausencia de estirpe o familia, condición o estado civil ${ }^{21}$.

iv) De aceptarse la interpretación restringida, entonces debería reconocerse que la procreación sería el único fin del matrimonio "ya que los esposos darían su consentimiento al ente orgánico que tendrían ante su vista" ${ }^{\text {"2 }}$, lo que debía rechazarse, porque el ser físico debía complementarse con requisitos propios de su esencia, como el estado civil y la estirpe.

e) Aplicó el aforismo: "donde el legislador no distingue, no es lícito al intérprete distinguir".

v) Por "idéntico" se entiende "lo que en la sustancia o realidad es lo mismo

puedan conducir a la nulidad de un matrimonio; a lo más, constituirán motivos para casarse, pero los motivos no son vicios del consentimiento, ni siquiera de los contratos ordinarios. Nuevamente, en estas argumentaciones, se hace presente el tradicional temor de abrir la puerta a la inestabilidad del vínculo matrimonial, por lo que considera esta posibilidad como peligrosa y excesiva (Ibíd., pp. 299-300). En similar sentido se pronunció Somarriva Undurraga, Manuel, Derecho de familia (Santiago de Chile, Editorial Nascimento, 1963), p. 32: "Se ha dicho, y con razón, que el alcance de la expresión error no puede limitarse al primer caso, que en la práctica es imposible que se presente; como afirma Demolombe, semejante equivocación no es admisible ni como truco en una obra teatral". No se pronunció en forma expresa en orden a si era o no partidario de la admisión del error en las cualidades, pero como ejemplos de ello planteó los siguientes: error en la calidad de hijo legítimo, en la religión, en el estado civil, en la virginidad de la mujer, en la honradez, en la fortuna y en los títulos. Citó estos ejemplos para clarificar que se trataba de un asunto relativo, y puso especial énfasis en el error en la nacionalidad, el que, normalmente, no tendría mayor influencia, pero que, podría pasar a tenerla en tiempo de guerra, si la nacionalidad del otro cónyuge es la perteneciente al país enemigo; en este caso, concluye, el error puede ser determinante.

${ }^{20}$ Pinochet Elorza, César, cit. (n. 8), pp. 26-35.

${ }^{21}$ Ibíd., p. 31.

${ }^{22}$ Ibíd. 
que otra cosa", mientras que "identidad" es "la cualidad de ser idéntica una cosa o persona, con otra", en consecuencia, entendía que no podía hablarse de identidad si entre el otro contrayente y la persona con quien se deseó contraer el vínculo existían diferencias sustanciales que impidiesen que se tratase del mismo sujeto de derecho.

vi) El N ${ }^{\circ} 1$ del artículo 33 era casi una transcripción literal del artículo 180 CCRf., y la doctrina nacional se basa en las enseñanzas de Pothier, las que, a poco andar, fueron desvirtuadas por el propio Napoleón en los debates originados con ocasión del proyecto de Código ${ }^{23}$.

vii) Finalmente, el artículo 35 de la Ley de matrimonio civil establecía la imprescriptibilidad de la acción de nulidad de matrimonio, salvo que se fundase, entre otros, en el $\mathrm{N}^{\circ} 1$ del artículo 33 . En su inciso $2^{\circ}$ se prescribía, como plazo de prescripción, un año contado desde que haya desaparecido el hecho que originaba el impedimento, lo que se entendía si se aplicaba tanto al error en la identidad física como al error en la persona social. De otro modo, se llegaría al absurdo de plantear que podría transcurrir un año sin que el yerro en la identidad física se descubriese, de ahí que una lógica interpretación de los preceptos legales llevaba a la admisión del error en la persona social en el $\mathrm{N}^{\circ} 1$ del artículo 33 .

Con respecto al error en las cualidades, el autor se pronunció por su rechazo $^{24}$, puesto que, las cualidades eran muy numerosas y de diverso género, por lo que de reconocerse su poder irritante, se abandonaría el matrimonio a la arbitrariedad más absoluta; las cualidades, por su propia naturaleza eran algo vagas e inciertas, incapaces de ser reducidas a número y medida ${ }^{25}$.

\section{Doctrina amplia.}

No son muchos los autores que durante la vigencia de la Ley de matrimonio civil de 1884 señalaban que el error en las cualidades se encontraba comprendido en el $\mathrm{N}^{\circ} 1$ del artículo 33 de la citada ley. En este sector minoritario encontramos a Meza Barros, Saavedra y Velasco.

Para Meza Barros ${ }^{26}$, si bien es cierto que señalaba que para la mayoría de la doctrina el error en la identidad comprendía el yerro sobre la identidad física

${ }^{23}$ Ibíd., pp. 33-34.

${ }^{24}$ Ibíd., p. 27.

${ }^{25}$ Esta opinión no es propia de las antiguas memorias, lo mismo puede encontrarse en memorias más modernas, véase: VARGAs Bugueño, Cristián, Los vicios del consentimiento en el derecho canónico y en el matrimonio civil de Chile y de algunos países latinoamericanos (memoria de grado, Pontificia Universidad Católica de Valparaíso, Valparaíso, 2000), p. 134.

${ }^{26}$ Meza Barros, Ramón, Manual de derecho de familia (2a edición, Santiago de Chile, Editorial Jurídica de Chile, 1989), p. 38. 
y en la persona social o civil, consideró que debía incluirse, también, el error en las cualidades. Partió de la base de un concepto amplio de "persona”, en la que ésta no sólo se limitaba a la individualidad física, sino que se extendía a sus atributos o cualidades. Agregó que la dificultad radicaba en establecer qué calidades singularizan y otorgan a una persona una individualidad distinta de las otras, pero argumentó que no debía tratarse de cualquier tipo de cualidad: "de tal modo que el defecto de esas calidades importe, podría decirse, una transformación de la personalidad" 27 . Continuó refiriéndose al criterio que debería aplicarse para apreciar la gravedad de las cualidades. Así, sostuvo que existían innumerables cualidades que, consideradas subjetivamente, para una parte puedan ser individualizadoras de la otra; puso como ejemplo, que la novia no tuviese las habilidades culinarias esperadas por el novio. Sugirió pensar en cualidades de tal relevancia cuya ausencia pudiese obstar, en términos verosímiles, a la celebración del matrimonio.

Meza Barros dio un paso más hacia adelante al sostener que el error en las cualidades debía viciar el consentimiento matrimonial: criticó la posición dominante en nuestra doctrina, al señalar que, sin mayores motivos, se excluía el error en las cualidades sustanciales, ya que no determinaba su identidad civil y propuso como ejemplo, el caso de una mujer que pensaba haberse casado con un hombre honrado, pero realmente había contraído vínculo con alguien que tenía un pasado criminal, o el caso de un hombre que creía haberse casado con una mujer honesta, en circunstancias que lo había hecho con una prostituta. El autor se rebeló ante la posición imperante en la doctrina, y como veremos, en la jurisprudencia, que negaba la posibilidad de accionar de nulidad en estos supuestos basándose en el error en la persona. Elogió la disciplina del error efectuada por el Código Civil de Alemania, al admitir el error en las cualidades si éstas son de tal naturaleza que si se hubiesen conocido y apreciado por el otro contrayente, el matrimonio no se habría celebrado. Se introdujo en una discusión que hoy mantiene ocupada a la doctrina que estudia el error en las cualidades: determinar el criterio que debe aplicarse para poder apreciar la entidad del error sobre las cualidades del otro contrayente, es decir, ¿se deben considerar parámetros objetivos o, por el contrario, corresponde aplicar un criterio subjetivo ${ }^{28}$ Sostuvo, y nuevamente teniendo en mente la disciplina realizada por el Código alemán,

${ }^{27}$ Ibíd.

${ }^{28}$ Véase: Mondaca Miranda, Alexis, Aplicación de un criterio objetivo-subjetivo en la apreciación de la entidad de las cualidades cuya falsa representación puede originar el error disciplinado en el $N^{\circ} 2$ del artículo $8^{\circ}$ de la nueva Ley de matrimonio civil, en Departamento de Derecho Privado Universidad de Concepción (coordinador), Estudios de derecho civil VII: Jornadas Nacionales de derecho civil, Concepción, 2009 (Santiago de Chile, Abeledo Perrot - LegalPublishing, 2010), pp. 297-312. 
que debían conjugarse elementos objetivos y subjetivos, es decir, debía considerarse la trascendencia que subjetivamente tenía el error para aquel que en él había caído, pero además, se necesitaba una ponderación objetiva: una debida significación racional del error sufrido.

Dentro de la doctrina más moderna, Saavedra ${ }^{29}$, comparte lo expresado por Meza Barros, lo que ya es apreciable en su definición de error determinante en la persona: "es aquel que recae en la identidad, situación jurídica o en las cualidades personales que, según la naturaleza del negocio, suelen ser tomados en consideración como relevantes para la formación de la voluntad del declarante". Ratificó su parecer al señalar que el error podía referirse a las cualidades o habilidades que son relevantes para el otro contratante, esto es, las que lo determinan para la realización del acto jurídico. Luego indicó que generalmente aquello ocurrirá en los actos intuitu personae, y como ejemplo de éstos, señala el matrimonio.

Para Velasco ${ }^{30}$ no bastaba con sancionar el error en la identidad física y social, sino que debía incluirse el error en las cualidades. Señaló que la mejor disciplina del error era la realizada en Alemania: "Sus normas son, en nuestra opinión, las más justas, equitativas y jurídicas. En líneas generales contempla el error en la declaración misma, el error en la identidad física del otro contratante y el error en las cualidades personales cuando éste es de tal entidad que sin él no se hubiese celebrado el matrimonio de haberse ponderado racionalmente la esencia del matrimonio". Claramente, la posición de Meza Barros, Saavedra y Velasco fue minoritaria durante la vigencia de la Ley de matrimonio civil de 1884 y, como examinaremos prontamente, no contó con el apoyo de nuestra jurisprudencia.

\section{JURISPRUDENCIA SOBRE EL $\mathrm{N}^{\circ} 1$ DEL ARTÍCULO 33 DE LA "LEY DE MATRIMONIO CIVIL" DE 1884: ACEPTACIÓN DE UN CRITERIO RESTRINGIDO}

Nuestros tribunales han optado por una interpretación restringida del $\mathrm{N}^{\circ} 1$ del artículo 33 de la Ley de matrimonio civil de 1884, esto es, nunca se aceptó, en sentencia firme y ejecutoriada, un error en la identidad civil, ni mucho menos, en las cualidades, como fundamento para acoger una petición de nulidad matrimonial. Lo anterior no nos puede dejar de llamar la atención, ya que, nuestra doctrina se encontraba dividida sobre el particular, como hemos visto en el apartado anterior, escenario que contrasta con la

${ }^{29}$ SaAvedra, Francisco, cit. (n. 6), p. 209.

${ }^{30}$ Velasco Letelier, Eugenio, De la disolución del matrimonio (Santiago de Chile, Editorial Jurídica de Chile, 1973), p. 95. 
uniformidad jurisprudencial. Al limitarse por los tribunales el error en la persona sólo al error en la identidad física, entendemos que ello contribuyó a la escasa jurisprudencia que sobre el tema que nos convoca se formó, lo que pudo haber influido eventualmente en la generalización de los fraudes de nulidad matrimonial basados en la incompetencia del Oficial de Registro Civil; quizás, más de una de estas nulidades pudo haber sido adecuadamente encausada por alguna especie de error en la persona diverso al error en la identidad física. En concreto, los siguientes son los fallos pronunciados por los tribunales chilenos sobre el error en el matrimonio durante la vigencia de la Ley de matrimonio civil de 1884: sentencia "Salas con Pereira", fallo "Fischer con Bendndorf", y sentencia "Butcher con Plaza”.

\section{Sentencia "Salas con Pereira"31.}

Este fallo, de fecha 15 de octubre de 1923, fue pronunciado por la Corte Suprema a raíz de la interposición de un recurso de casación en el fondo. Se trató de una sentencia que se pronunciaba sobre la falta de un libre y espontáneo consentimiento en atención a la presencia de un error en la persona, recayendo la falsa representación en el nombre y en la clase de filiación y parentesco del demandado. La recurrente, Elvira Rogat Salas, amparándose en los artículos 32, $33 \mathrm{~N}^{\circ} 1$ y 2, 34, y 35 de la Ley de matrimonio civil, solicitó la declaración de nulidad del matrimonio celebrado con el recurrido, Manuel Pereira Aránguiz, de fecha 30 de noviembre de 1907. La petición se fundamentaba en que se habría producido un error en la persona del otro contrayente, al considerar la recurrente que se casaba con Manuel Pereira Aránguiz, pero éste no tenía verdaderamente ese nombre, no era hijo legítimo, ni se encontraba emparentado con la familia Aránguiz y Fredes. Además, basó su recurso en el $\mathrm{N}^{\circ} 2$ del artículo 33, esto es, en el vicio de fuerza, ya que su propio padre, la habría amenazado con matarla si no consentía en el matrimonio, puesto que entendía que el futuro marido era arquitecto y estaba pronto a recibir una herencia de sus presuntas tías Aránguiz.

Por su parte, Pereira Aránguiz, en primera instancia, fue declarado rebelde, y en tal estado de cosas se pronunció la sentencia de primer grado dictada por un Juzgado de Letras de Santiago ${ }^{32}$, de fecha 17 de agosto de 1921. El tribunal declaró lo siguiente: el error en la persona del otro cónyuge podía estar referido a su persona misma, a su identidad o a las cualidades que se le atribuyen; el $\mathrm{N}^{\circ} 1$ del artículo 33 no era aplicable exclusivamente al error en la persona física, no debiendo descartarse, como causal de nulidad, el error

${ }^{31}$ Sentencia de la Corte Suprema de 15 de octubre de 1923, en Revista de Derecho y Jurisprudencia, 22 (1925), II, sección 1a, pp. 538-547.

${ }^{32}$ No se indica el tribunal específico de primera instancia que dictó la sentencia. 
en las cualidades; la noción de p e r s o n a no se limitaba sólo al individuo físicamente considerado, sino que incluía "las condiciones que determinan el lugar que debe ocupar en la sociedad", por lo tanto, en la especie se había verificado un error en la persona, específicamente en la identidad del otro cónyuge, el que provocaba la nulidad del matrimonio celebrado por las partes $^{33}$. Se reservaron los derechos de la parte gananciosa para solicitar reivindicación e indemnización de perjuicios.

Elevado en consulta el fallo de primera instancia, fue revisado por la Corte de Apelaciones de Santiago, la que el 28 de septiembre de 1922 revocó el fallo consultado, en razón de los siguientes argumentos: el error alegado no se refería a la persona del demandado, sino a sus cualidades o relaciones de familia que se le atribuyeron y que indujeron a la actora a casarse y el error en tales cualidades no viciaba la voluntad, según el $\mathrm{N}^{\circ} 1$ del artículo 33, a diferencia de lo que sucedía con el error en la identidad física del contrayente. Agregó como fundamento la Corte que "el demandado se encontró personalmente presente en el momento del matrimonio, e hizo vida marital durante varios años con la demandante" ${ }^{34}$.

Esta sentencia es atacada por la vía del recurso de casación en el fondo. Los argumentos del recurrente fueron: a partir de la definición de p e r $\mathrm{s}$ o $\mathrm{n}$ a del artículo $55 \mathrm{CC}$, se entendía que era tal, no el individuo en sí, sino éste como sujeto de derecho. Por esto no se podía imaginar una persona sin e s t i r p e ni condición, y la es tir pe es la familia y la co ndición el estado civil, de ello se seguía que ambos elementos se integraban en el apellido, "en el nombre patronímico que distingue e individualiza a cada ser humano que vive y obra en una sociedad civilizada". Se reforzaron estas ideas recurriendo a la definición de la palabra e $s \mathrm{t}$ i r p e que hacía el diccionario ${ }^{35} \mathrm{y}$ al origen etimológico de pe r s o n a que la distingue de individuo físico, y se recurrió al sentido de la palabra p e r s o n a en latín, que pasó de representar la máscara de los actores a significar el rol que un sujeto ocupaba en la sociedad.

En apoyo de su petición, y para distinguir p e r s o $\mathrm{n}$ a de h o m b r e, el recurrente citó a Claro Solar, el que seguía a Toullier, Duvergier, BaudryLacantinerie y Houques-Fourcade. Considerando que en la noción de "persona”, en su sentido natural y técnico, se incluía su e s t i r p e y c o n d i c i ó n, la resolución recurrida había infringido el artículo 55, debido a que la e $s$ t i r p e se individualiza por un nombre patronímico inmutable y hereditario, el que se origina del nacimiento, de la legitimación o de reconocimientos posteriores, por esta razón, nadie puede adquirirlo, modificarlo o perderlo a

${ }^{33}$ Ibíd., p. 540, no se pronuncia el sentenciador sobre el vicio de fuerza, ya que a su respecto, la actora no acreditó en forma legal la procedencia de la amenaza alegada.

${ }^{34}$ Ibíd.

${ }^{35}$ Ibíd., p. 541. 
su voluntad. Concluía afirmando que: “por último, todos los autores están de acuerdo en que el apellido es imprescindible, activa y pasivamente, porque distingue a las personas, porque está incorporado a ellas, porque no es bien patrimonial sino elemento de la personalidad que, desprendido de ella, pierde toda significación para convertirse en un vocablo, en una expresión que no se distingue de las otras del lenguaje" 36 .

A continuación aludía al artículo 215 CP., que sancionaba el delito de usurpación de nombre, se señalaba que existían dos elementos fundamentales del nombre: es de la esencia de toda persona tener un nombre propio y que éste sólo se adquiere por medios legales. Regulaba la adquisición y conservación del nombre el artículo 25 del título $4^{\circ}$ del Reglamento para la ejecución de las Leyes de Registro Civil y de matrimonio civil, en sus números 1, 2, 3 y 4 , se refería a la edad, sexo, estirpe y condición del recién nacido. Continuó señalando que se habían infringido los artículos 20, 24 y 55 CC., ya que la ley había definido p e r s o n a y del contexto general de la legislación se desprendía que el nombre es esencial a toda persona dado que determina su estirpe o familia. La infracción de las normas influía sustancialmente en lo dispositivo del fallo "ya que, aplicándolas correctamente, US. I. habría llegado a la conclusión de que errar en cuanto al nombre es errar en cuanto a la persona civil, que nace con un nombre, como nace con un sexo, siendo uno y otro requisitos constitutivos de ella misma, inseparables de su esencia, imprescriptibles en el tiempo e inmutables también mientras no recaiga sobre el particular una sentencia pasada en autoridad de cosa juzgada”.

También se habría infringido, el ya citado artículo 55 y el 304 CC. La primera norma exigiría que toda persona debía tener una c o n d i c i ó $\mathrm{n}$, es decir, un estado civil, el que es definido por la segunda, empleando la palabra c a l i d a d, la que es sinónimo de c o n d i c i ó $\mathrm{n}^{37}$. Por lo anterior, tampoco es posible concebir una persona sin condición o sin estado civil, entonces, errar sobre el estado civil es errar sobre la persona misma, porque son conceptos inseparables; luego, debía anular un matrimonio el error sobre la condición de hijo ilegítimo.

Además, según el $\mathrm{N}^{\circ} 4$ del artículo 25 del Reglamento ${ }^{38}$, el nombre debía

${ }^{36}$ Ibíd., p. 542.

${ }^{37}$ En efecto, sostenía el recurrente que "calidad" significaba "lo que constituye el estado de una persona, su naturaleza, su edad, y demás circunstancias y condiciones que se requieren para entrar en un cargo o jerarquía", mientras que "condición” implicaba "la calidad del nacimiento o estado de los hombres", Ibíd.

${ }^{38}$ Artículo 25 No 4 del Reglamento de 24 de octubre de 1884: "Los nombres, apellidos, nacionalidad, domicilio y profesión u oficio de los padres, si el recién nacido fuese hijo ilegitimo y si se pidiese su inscripción como tal. Si se pidiere la inscripción del recién nacido como hijo ilegitimo o de padres no conocidos, no se expresará quién sea el padre y 
ser dado o consignado no por mero capricho, sino con estricta sujeción al estado o condición del recién nacido, de ahí que al errar sobre la condición o estado civil se producía un error en la persona, puesto que, para ser tal, era necesario tener una condición; así, la infracción de ley influyó sustancialmente en lo dispositivo del fallo porque no consideró comprendido dentro de la noción de p e r s o n a la condición de ésta, de ahí que no aceptó la falta de un libre y espontáneo consentimiento por error en la persona basado en el yerro en el estado civil.

En concepto del recurrente, se habría infringido el artículo $102 \mathrm{CC}$. que define el matrimonio, ya que éste tiene tres fines: vivir juntos, procrear y auxiliarse mutuamente. Es decir, no solo procrear, dado que el matrimonio implica la unión de dos personas y el enlazamiento de sus respectivas familias. El estado civil y la posición social son elementos decisivos del contrato, no es lo mismo contraer matrimonio con un aventurero, con un miembro honorable de una familia honrada, o con el hijo legítimo de ciertos padres, por lo que en este contexto, puede apreciarse la dificultad en lograr los fines del matrimonio: vivir juntos y auxiliarse mutuamente; "si lejos de coparentar con una familia digna se une la mujer con un anónimo que no tiene derecho al nombre que lleva ni a la posición de que presume" ${ }^{39}$.

Finalmente se alegó la violación de los artículos $33 \mathrm{~N}^{\circ} 1$ de la Ley de matrimonio civil y 23 y $24 \mathrm{CC}$. No procedía distinguir en la aplicación del $\mathrm{N}^{\circ}$ 1 del artículo 33 entre error en la identidad física y error en las cualidades, ello por el viejo aforismo "donde la ley no distingue no es lícito al hombre distinguir". En la historia fidedigna del establecimiento de la norma no se apreciaba modificación al texto del artículo 48 del proyecto ni se produjo debate, tanto en la Cámara de Diputados como en el Senado, por lo que debe recurrirse a las definiciones del vocablo e $\mathrm{n} \mathrm{t}$ i d a d y p e r s o $\mathrm{n}$ a y al contexto de otras leyes que versen sobre el mismo asunto y al espíritu general de la legislación. Luego de señalar las definiciones que el diccionario ofrecía

quién sea la madre. Pero se hará la enunciación si la persona que se atribuye la paternidad o maternidad pide personalmente o por medio de apoderado constituido en forma legal, que se inscriba a su nombre. Respecto a los recién nacidos, abandonados o expósitos, se expresará la hora, día, mes, año y lugar en que el niño hubiere sido hallado o expuesto, su edad aparente, las señales particulares o defectos de conformación que le distingan, asi como los documentos u objetos que sobre él se hubieren encontrado y que puedan servir para la futura identificación de su persona".

${ }^{39}$ Sentencia de la Corte Suprema de 15 de octubre de 1923, cit. (n. 31), p. 543. 
de la palabra id e $\mathrm{n}$ i d a d ${ }^{40}$ y de citar la doctrina de Pothier ${ }^{41}$, se afirmó que al restringir la aplicación del $\mathrm{N}^{\circ} 1$ del artículo 33 al error en la identidad física, se llegaba al absurdo de regular un caso que jamás se producirá, agregando en su favor toda la doctrina gala crítica de la interpretación de Pothier, especialmente a Delvincourt y su ejemplo de aquel que desea desposarse con la hija de un individuo que no conoce, y se casa con una mujer que afirma ser la hija de dicho individuo, ello ya que "el ejemplo que pone parece hecho para mi mandante, que creyó desposarse con el hijo legítimo de don Raimundo

${ }^{40}$ Ibíd.: "Dícese idéntico de lo que en la sustancia o realidad es lo mismo que otra cosa, y así se llama ecuación idéntica en matemáticas aquella en que es perfecta la igualdad de ambos miembros. La identidad es por lo tanto, 'la cualidad de ser idéntica una cosa con otra". Por ello se concluye que "De manera que no habrá identidad si entre la persona con quien se contrajo matrimonio y aquella con quien se quiso contraerlo hay diferencias sustanciales que hagan de ambas personas dos seres distintos en derecho".

${ }^{41}$ Este autor consideraba que el tenor del artículo 180 CCFr. se refería sólo a la persona física. Pothier, Robert-Joseph, Tratado del contrato de matrimonio (trad. Noguera Mariano y Carles, Francisco, Barcelona, Imprenta y Litografía de J. Roger, 1846), pp. 132-135, distinguía entre error en la persona y error acerca de la calidad de la misma. Respecto al primero, consideraba que excluía el consentimiento, lo que justificaba la nulidad del matrimonio, ya que lo esencial era que un hombre y una mujer se quisiesen casar, lo que no ocurría si la mujer con la que se había casado un hombre era diversa, en términos físicos, de lo que se creía. Proponía el siguiente ejemplo pensando en un supuesto de sustitución de personas: "Si con el propósito de contratar con María y de casarme con ella, doy mi palabra de matrimonio a Juana que se hace tomar por María; es evidente que no hay consentimiento, y que el matrimonio que he contraído con Juana que yo creía ser María, es nulo por esta razón; porque en esta especie no se halla el concurso de las dos voluntades en una misma cosa ("duorum in idem placitum consensus"), ya que si Juana quiso casarse conmigo, yo no quise casarme con Juana [...] al decir que la tomaba por esposa, no era a ella a quien se lo decía, sino a María”. Con relación al error en la calidad de la persona, en su opinión, ocurría todo lo contrario, ya que no era de la esencia que la mujer tuviese las cualidades esperadas por el hombre, era suficiente con que no se errase en la identidad física. Señalaba como ejemplo, el que a continuación se indica: "Si me hubiese casado con María creyéndola noble, aun cuando en realidad fuese de la más baja condición, ó creyéndola virtuosa fuese prostituta, ó creyéndola de buena reputación estuviese infamada por una sentencia judicial; el matrimonio no dejará de ser válido, á pesar de este error”. Es decir, para Pothier el error en las cualidades no tenía la entidad necesaria para viciar el consentimiento, ya que la consideración sobre la presencia o ausencia de determinadas cualidades no se comprendía dentro de la esencia del matrimonio, esta clase de error no destruye el consentimiento, se trataba de un arrepentimiento, pero la naturaleza indisoluble del contrato no admite retractación ni rescisión. Tampoco otorgaba poder relevante al error en las calidades en el evento en que haya sido inducido por dolo. La única excepción reconocida por Pothier a esta regla era el caso de matrimonio con una persona esclava a la que se consideraba como libre. 
Pereira y doña Isabel Aránguiz, a quienes no conocía, y resultó casada con el hijo de otra persona"42.

Otro argumento fue esgrimido por el recurrente: la presunta infracción del artículo 1562 del Código Civil, pues no es lógico concebir que el legislador dicte normas que sean inútiles, en razón de su imposible o muy difícil aplicación.

En definitiva, al no interpretar el $\mathrm{N}^{\circ} 1$ del artículo 33 de la Ley de matrimonio civil según las reglas del párrafo $4^{\circ}$ del "Título Preliminar" del Código Civil, limitándose el sentenciador al error en la identidad física, se violaba el citado artículo y el artículo 23 y 24 del mismo Código, "ya que el espíritu general de nuestra legislación, de las similares extrajeras y del derecho canónico, las definiciones legales, la jurisprudencia de los tribunales civiles y eclesiásticos, el común sentir de los tratadistas y hasta la equidad natural, demuestran que el error contemplado en la ley de matrimonio civil es el que se refiere a la persona civil, constituida por las cualidades esenciales que le fjan su lugar permanente en la sociedad, o sea, su estado civil"43.

La Corte va rechazando los fundamentos del recurso de casación:

a) El error disciplinado en el $\mathrm{N}^{\circ} 1$ del artículo 33 se refería al individuo mismo, y no a sus cualidades, como la edad, sexo, estirpe o condición. Un yerro sobre estas cualidades no anulaba el matrimonio, porque no obstaba al consentimiento protegido en la Ley de matrimonio civil. $\mathrm{Al}$ referirse el $\mathrm{N}^{\circ}$ 1 del artículo 33 al error en la identidad física no se infringía el artículo 55 CC., ni los artículos 24 y 25 del mismo texto relativos a la interpretación de la ley, ya que el sentido de la norma es claro y no existen en ella pasajes oscuros o contradictorios.

b) No se violaron los artículos 55 y 304 CC. al no aceptar que si se yerra sobre la condición o estado de una persona, se yerra sobre ésta misma porque para ser persona debe tenerse una edad, un sexo, una estirpe y una condición; "cabe observar que la palabra persona en su acepción más general, indica simplemente la capacidad de derechos y en su acepción más restringida, indica la posición legal que el hombre ocupa en la familia y en la sociedad, o sea, lo que constituye el estado civil que define el artículo 304 del Código citado". Se agregó que este artículo no se aplicaba en la especie por lo que no pudo haber sido infringido.

c) $\mathrm{Al}$ no establecer, en parte alguna, la sentencia recurrida que el único fin el matrimonio era la procreación, no procedía la infracción del artículo 102 CC.

d) Tampoco se infringieron los artículos $33 \mathrm{~N}^{\circ} 1$ de la Ley de matrimonio

\footnotetext{
${ }^{42}$ Sentencia de la Corte Suprema de 15 de octubre de 1923, cit. (n. 31), p. 544.

${ }^{43}$ Ibíd., p. 545.
} 
civil, 23 y 24 CC. Respecto a la primera, si el sentido de la ley es claro, no se desatenderá su tenor literal a pretexto de consultar su espíritu, y es claro el sentido del citado $\mathrm{N}^{\circ} 1$, al prescribir "error en cuanto a la identidad de la persona del otro contrayente", o sea, error esencial ya que no existe consentimiento, pero la norma no aludía al error en las cualidades "lo que se conforma, por otra parte, al espíritu democrático de nuestra legislación que tiende a la nivelación social”" ${ }^{\prime 4}$.

Por todas estas consideraciones se rechazó el recurso de casación en el fondo, limitando la aplicación del artículo $33 \mathrm{~N}^{\circ} 1$ sólo al error en la identidad física, descartando el error en la persona social y en las cualidades del otro contrayente. El fallo fue acordado con el voto en contra del ministro Cisternas Peña, pero lamentablemente, no se indican sus argumentos ${ }^{45}$.

\section{Sentencia "Fischer con Benndorf" 46}

En idéntico sentido, se pronunció la sentencia de 26 de septiembre de 1939. Se trató de un fallo pronunciado por la Corte Suprema con ocasión de la presentación de un recurso de casación en el fondo. El demandante, don Ricardo Fischer, presentó ante el Tercer Juzgado de Mayor Cuantía de Santiago acción de nulidad dirigida en contra de su presunto cónyuge, doña Ilse Benndorf. El matrimonio se celebró en Berlín el 30 de junio de 1926. Funda su acción en los artículos $15^{47}$ de la Ley de matrimonio civil de 1884 y en los parágrafos 1333 y 1339 inciso $1^{\circ}$ del Código Civil alemán de 1900. En virtud de la norma nacional, el matrimonio celebrado en país extranjero, producía en Chile los mismos efectos, como si se hubiese celebrado en Chile, en la medida que se cumpliesen con los requisitos de existencia y validez prescritos por la ley extranjera. De ahí la necesidad, en el caso sometido a decisión del tribunal, de conocer el estado de la materia en el derecho civil alemán. En particular, el parágrafo 1333 del Código alemán consagraba el error en las cualidades, siempre que hubiese sido determinante en la celebración del matrimonio.

El actor argumentó que al casarse con Ilse Benndorf, erró en las cualidades de ésta, y que si las hubiese conocido y dada la naturaleza del vínculo matrimonial, no habría celebrado el contrato. En efecto, señaló que se dirigió a Alemania con el objetivo de encontrar una mujer que fuese apta para compartir su vida en Chile, pero su actual cónyuge "no posee las condiciones orgánicas y espirituales para poder permanecer sin grave detrimento de su salud

\footnotetext{
${ }^{44}$ Ibíd., p. 546.

${ }^{45}$ Ibíd., p. 547.

${ }^{46}$ Gaceta de los Tribunales (1939, $2^{\circ}$ semestre), pp. 182-188.

${ }^{47}$ Ibíd.
} 
y bienestar en estepaís" ${ }^{38}$. Previendo la aplicación del artículo 121 CC., por el cual el matrimonio celebrado en país extranjero sólo podrá disolverse en Chile de acuerdo a la legislación nacional, indicó que era un conocido principio de las ciencias jurídicas que la disolución de un acto o contrato es una institución esencialmente diversa de su cancelación o declaración de nulidad ${ }^{49}$.

En la contestación de la demanda, se reconocieron tanto la efectividad de los hechos alegados por el actor como los fundamentos de derecho en que se apoyaba. Las partes mantuvieron sus posiciones en los escritos de réplica y de dúplica.

En este estado de cosas, se dictó sentencia de primera instancia, acogiéndose la acción de nulidad, basándose, entre otras normas, en el artículo 15 inciso $1^{\circ}$ de la Ley de matrimonio civil. El fallo fue elevado en consulta ante la Ilustrísima Corte de Apelaciones de Santiago, la que ordenó que se procediese al informe del fiscal. Éste, evacuando su informe, solicitó la revocación del fallo consultado, ya que no procedía aplicar en Chile el parágrafo 1333 del Código alemán, puesto que la acción se encontraría prescrita, dado que según el parágrafo 1339 del mismo cuerpo normativo, el plazo de prescripción era de seis meses contados desde el momento en que el esposo víctima descubrirse el engaño, plazo que había largamente transcurrido.

El fallo de segunda instancia revocó la declaratoria de nulidad, indicándose lo siguiente:

a) Que efectivamente, según el artículo 15 de la Ley de matrimonio civil de 1884, el matrimonio celebrado en país extranjero produce efectos en Chile siempre que se haya celebrado de acuerdo a las leyes de dicho país, pero ello sólo autorizaba para que a los contrayentes se les reconociesen los mismos derechos y se les impusiesen las mismas obligaciones que establecía respecto de los cónyuges el libro I, títulos $6^{\circ}$ a $16^{\circ} \mathrm{CC}$.

b) Fuera de la muerte natural o presunta, en Chile el matrimonio se disolvía por declaración de nulidad pronunciada por autoridad competente.

c) Por lo anterior, la palabra "disolución", referida al matrimonio, comprendía el concepto "anular"; luego, entre éstas existía una relación de género a especie, siendo el género la primera, y la especie, el segundo.

d) El matrimonio celebrado en país extranjero y que, según las leyes de dicho país, pudiera disolverse en él, no podía, sin embargo, disolverse en Chile, sino en conformidad a la ley chilena.

e) La causal fundamento de la nulidad alegada, error en las cualidades, regulada en el parágrafo 1333 del Código alemán, "no figura en ninguna de las leyes chilenas que rigen sobre el particular”.

\footnotetext{
${ }^{48}$ Ibíd., p. 182.

${ }^{49}$ Ibíd., pp. 182-184.
} 
f) Lo indicado previamente se reafirmaba al considerar el tenor del artículo 120 CC., en cuya virtud un matrimonio ya disuelto en país extranjero, no habilitaba en Chile, a ninguno de los cónyuges, para casarse mientras viviese su ex cónyuge ${ }^{50}$.

Por lo tanto, reconociendo que en Alemania era procedente la nulidad del matrimonio por error en las cualidades, en virtud de lo establecido, se rechazó la demanda de nulidad de matrimonio. En contra de la sentencia de segunda instancia, se dedujo recurso de casación en el fondo, solicitando la revocación de dicho fallo. Los argumentos en los que se sostiene el recurso fueron los siguientes: la sentencia impugnada infringía la ley al establecer que el tenor del artículo 15 de la Ley de matrimonio civil venía a significar que los que contraían matrimonio en país extranjero, en conformidad a las leyes del mismo país, se les reconocían e imponían los mismos derechos y obligaciones correspondientes a los que se casaban en Chile. Esto se explicaba al considerar el inciso $1^{\circ}$ del artículo 19 CC., y el texto del citado artículo 15 , el que establecía que en Chile producía efectos el matrimonio celebrado en país extranjero en conformidad a las leyes de dicho país, pero no indicaba que se refería sólo a los derechos y obligaciones de los cónyuges, como pretendía la sentencia recurrida, sino que también abarcaba "la determinación previa de si el vínculo matrimonial se había ajustado o no a lo que estatuía la legislación bajo cuyo imperio se celebró" ${ }^{51}$. Además, la sentencia recurrida citó los artículos 120 y 121 de la Ley de matrimonio civil, estableció que la disolución del matrimonio, incluso el celebrado en el extranjero, para que habilitase a los cónyuges a volver a casarse en nuestro país, debía haberse producido por muerte natural o presunta o por declaración de nulidad pronunciada por autoridad competente. Se agregaba que "disolver” era el género y “anular" la especie, y que, como la nulidad por error en las cualidades no era aceptada en ley nacional alguna, debía rechazarse la demanda. A esto se retrucó señalando que la acción deducida por el actor se fundaba en una causal de disolución, como lo era la nulidad, aceptada en el ordenamiento chileno, en apoyo de ello debía estarse al texto del artículo 37 de la Ley de matrimonio civil ${ }^{52}$. Es decir, la Corte habría confundido la causal de disolución; la declaración de nulidad, con los fundamentos que la originan, el error en las cualidades. Finalmente, se indicó que debió admitirse la demanda, puesto que nuestra legislación aceptaba como motivo para impetrar la nulidad de un matrimonio el error en cuanto a la identidad de la persona, citando en soporte de su

${ }^{50}$ Ibíd., p. 184.

${ }^{51}$ Ibíd.

${ }^{52}$ Artículo 37 LMC. de 1884: "El matrimonio se disuelve: $1^{\circ}$ por la muerte natural de uno de los cónyuges; y $2^{\circ}$ por la declaración de nulidad pronunciada por autoridad competente". 
alegación el artículo 32 y $33 \mathrm{~N}^{\circ} 1$ de la Ley de matrimonio civil. La última norma hablaba de "identidad", pero no especificaba si se refería a la identidad física o moral, de lo que se seguía que, si el legislador no había distinguido, no era lícito al intérprete hacerlo.

Por estas consideraciones, se habría transgredido el artículo 121 CC., infracción que había influido sustancialmente en lo dispositivo del fallo, ya que de haberse aplicado en forma correcta la norma se habría declarado la nulidad de matrimonio en virtud de lo prescrito en el parágrafo 1333 del Código alemán. La Corte Suprema resolvió rechazar el recurso de casación deducido, fundando su decisión en:

i) El fallo impugnado no infringió el artículo 15 de la Ley de matrimonio civil de 1884, dado que no desconoció el matrimonio celebrado en Alemania en conformidad a las leyes germanas; el sentenciador sólo había interpretado el parágrafo 1333 del Código alemán, el que establecía la nulidad matrimonial por error en las cualidades, rechazando su aplicación, por lo que la infracción producida sería de este último artículo.

ii) Cualquiera que haya sido la interpretación hecha del artículo 121 del Código Civil, norma también pretendidamente infringida, la infracción no había influido sustancialmente en lo dispositivo del fallo, ya que la nulidad matrimonial pedida se fundaba en el parágrafo 1333 del Código Civil alemán.

c) Debía considerarse que el recurso de casación es de derecho estricto, por lo que debía estarse al análisis de las normas legales infringidas que habían influido en la sentencia, y el fundamento de la acción era la interpretación del precepto del Código alemán y no la de ninguno de los preceptos señalados como infringidos en el recurso ${ }^{53}$.

El Ministro Rondanelli y el abogado integrante Alamos, para justificar su rechazo al recurso, se basaron únicamente en lo que se pasa a indicar:

i) Sin perjuicio de lo que se disponía en el artículo 15 de la Ley de matrimonio civil, la amplitud de los efectos en Chile del matrimonio celebrado en país extranjero se limitaba, en lo tocante a su disolución, por lo establecido en el artículo 121 CC., razón por la cual, tales matrimonios podrán disolverse en Chile sólo en conformidad a la ley chilena.

ii) La nulidad de matrimonio en Chile procedía únicamente por las causales reguladas en los artículos 29, 30, 31, 32, 32 y 33 de la Ley de matrimonio civil.

iii) La causal esgrimida por el actor no se apoyaba en ningún de los artículos mencionados, sino en una norma del Código alemán, precepto no infringido y que no era materia del recurso de casación presentado.

iv) Conforme al artículo 14 CC., la ley chilena obligaba a todos los

${ }^{53}$ Gaceta, cit. (n. 46), pp. 186-187. 
habitantes de la República, inclusos los extranjeros y dado que en Chile no podía disolverse el matrimonio por la causal que establecía el parágrafo 1333 del Código Civil de Alemania, al no aceptarse la acción de nulidad deducida, se había otorgado una correcta interpretación al texto del artículo 121 CC. y al artículo 15 de la Ley de matrimonio civil, únicas causales en las que se fundaba el recurso que se rechazaba ${ }^{54}$.

\section{Sentencia "Butcher con Plaza" 55 .}

Con fecha seis de julio de 1943, la Corte de Apelaciones de Santiago, conociendo de un recurso de apelación, dictó sentencia rechazando la acción de nulidad matrimonial fundada en error en la persona. En primera instancia, el demandante, Leslie Butcher Wood expuso que contrajo matrimonio con la demandada, Laura Plaza, el 24 de agosto de 1938, pero este contrato adolecía de nulidad relativa en atención a lo prescrito en el $\mathrm{N}^{\circ} 1$ del artículo 33 de la Ley de matrimonio civil, esto es, error en la persona. Además, alegó que concurría el impedimento de vínculo matrimonial no disuelto. Por no guardar relación con el objetivo de la presente investigación, omitiremos desarrollar lo resuelto respecto a la bigamia, limitándonos sólo al error en la persona.

En concepto del recurrente no procedía limitar el $\mathrm{N}^{\circ} 1$ del artículo 33 al error en la identidad física del otro contrayente, debiendo aplicarse al error en la persona civil o social. Agregaba que una interpretación restrictiva de la norma implicaba realizar una distinción no efectuada por el legislador y la transformaba en inaplicable por la dificultad o imposibilidad de la producción de un error en la identidad física. Por tanto, para evitar que la norma fuese letra muerta debía buscarse una nueva interpretación que le otorgase utilidad, lo que sucedía abarcando el error en la persona civil. Esto se ratificaba si se consideraba que el plazo de prescripción establecido, de un año, resultaba excesivo si la norma se limitaba sólo al error en la identidad física. La interpretación restrictiva conducía a considerar que el matrimonio tenía por fin cohabitar y procrear, excluyendo otros fines propios, como vivir juntos y auxiliarse mutuamente ${ }^{56}$. En concreto, el error alegado recaía en el nombre del cónyuge, en el nombre de los suegros, en el estado civil del cónyuge y en la edad de ésta. Los argumentos alegados por el recurrente fueron: de erró en el nombre del cónyuge, puesto que el actor creyó casarse con Elena Laura Plaza de los Reyes Condell, pero en realidad contrajo vínculo con Laura Plaza Plaza; el error acerca del nombre de los suegros ocurrió al creer que éstos eran Alfredo Plaza de los Reyes y Amelia Condell, pero realmente se

${ }^{54}$ Ibíd., pp. 187-188.

${ }^{55}$ Sentencia de la Corte de Apelaciones de Santiago, de 6 de julio de 1943, en Revista de Derecho y Jurisprudencia, 41 (1944), II, sección 2a, pp. 17-24.

${ }^{56}$ Ibíd., p. 21. 
llamaban Amador Plaza y Griselda Plaza; también se produjo un yerro en el estado civil del cónyuge al considerar que era soltera, pero se alegaba que su verdadero estado civil era el de casada; operó error en la edad del cónyuge puesto que ésta al momento de casarse afirmó que había nacido el 14 de agosto de 1906, por lo que tendría 32 años, pero su auténtica edad era 49. Continuó indicando que los atributos de la personalidad eran la capacidad, el nombre, el estado civil y la nacionalidad. Éstos conformaban la persona misma, y de ellos se erró en tres: capacidad, nombre y estado civil.

En la contestación de la demanda, se solicitó el rechazo de ésta, en atención a lo siguiente: los padres de la demandada eran, efectivamente, los que se indicaron en el acta de manifestación del matrimonio, y sus nombres fueron los expresados en su primer matrimonio, por consideraciones sociales " no se consideró oportuno darle los nombres verdaderos de suspadres, en atención a que es ilegitima; cuando se dieron los datos en el primer matrimonio, ella era una muchacha, no siendo responsables de que se dieran datos erróneos respecto de su personalidad, pero al correr del tiempo vino a darse cuenta de estos hechosy entonces usó sus verdaderos apellidos con los cuales se casó con el demandante" ${ }^{\text {"57 }}$; el matrimonio no era anulable por error en la persona, ya que el $\mathrm{N}^{\circ} 1$ del artículo 33 se refería al error en la identidad de la persona, esto es, al error en la persona física, lo que según el léxico apuntaba a la cualidad de ser de una persona o cosa, la misma que se supone o se busca.

El Tribunal de segunda instancia resolvió no dar lugar a la demanda de nulidad de matrimonio, ello porque:

a) El artículo 55 CC., al definir "persona", se refería a todos los individuos de la especie humana, con independencia de su edad, sexo, estirpe o condición, o sea, bastaba que se tratase de un nacido de mujer "sin consideración a los accidentes, cualidades o atributos sociales, civiles, morales o meramente materiales que pueda tener ese individuo" ${ }^{158}$.

b) Por su parte, el $\mathrm{N}^{\circ} 1$ del artículo 33, al señalar "identidad de la persona", hacía referencia a la "identidad" del sujeto físicamente considerado, haciendo abstracción de toda calidad referente a su edad, sexo, estirpe o condición. En la "estirpe" se incluye el nombre y el estado civil, y, en la condición, la situación moral, social, etc.

c) Si bien es cierto que el $\mathrm{N}^{\circ} 1$ del artículo 33 no distinguía entre persona física o social, ello no implicaba que la norma comprendiese ambas clases, sino que el precepto se aplicaba a la persona físicamente considerada "que es el que por definición constituye la persona dentro de nuestra legislación" 59 .

\footnotetext{
${ }^{57}$ Ibíd., p. 22.

${ }^{58}$ Ibíd., p. 23.

${ }^{59}$ Ibíd.
} 
Por estas consideraciones, y en concordancia con los dos fallos anteriormente analizados, se rechazó la petición de nulidad matrimonial fundada en el error en la identidad civil o social.

\section{COMENTARIO SOBRE LA JURISPRUDENCIA NACIONAL ACERCA DEL ERROR EN EL MATRIMONIO}

Pinochet ${ }^{60}$ ha indicado que nuestra jurisprudencia, para aceptar exclusivamente el valor dirimente del error en la identidad física recurre a su "palabra de autoridad", sin entregar mayores fundamentos. No estamos de acuerdo con la opinión del autor, ya que, si bien es cierto, no puede afirmarse que exista una amplia gama de fundamentos en las resoluciones analizadas, sí se han indicado razones diversas al argumento de autoridad para descartar la procedencia del error en la persona social y del error en las cualidades, aunque su desarrollo no pueda calificarse de extenso. Estas razones son: en ninguna norma de nuestro ordenamiento se reconoce el error en las cualidades como una causal de nulidad de matrimonio; en aplicación del elemento gramatical de interpretación de la ley, es claro el sentido de la norma al prescribir "error en la persona", expresión referida al error en la corporeidad del otro contrayente; el espíritu democrático de nuestra legislación impide aceptar el error en las cualidades ya que aquella tiende a la nivelación social; los errores diversos al yerro sobre la identidad no tienen la entidad suficiente para viciar el consentimiento; $y$, la noción de persona del artículo 55 CC. se refiere a todo nacido de mujer con independencia de sus cualidades, accidentes o atributos.

\section{En ninguna norma de nuestro ordenamiento se reconoce el error en las} cualidades como una causal de nulidad de matrimonio.

Con relación al primer fundamento, es efectivo que en ninguna norma de nuestra primitiva Ley de matrimonio civil se reconocía, en forma expresa, el error en las cualidades como una causal de nulidad de matrimonio. Pero sabido es que la no mención explícita de una determinada institución jurídica, aunque ello sea un factor de relevancia que no pueda desconocerse, no es decisiva para resolver su aceptación o rechazo en un determinado ordenamiento jurídico. En efecto, es viable que la regulación de una figura jurídica sea tácita, en cuyo caso, es la propia jurisprudencia la principal mandatada

${ }^{60}$ Explica Pinochet Elorza, César, cit. (n. 8), p. 29, que: "Nuestra jurisprudencia [...] Pasando por casi la totalidad de los tratadistas chilenos y extranjeros, y por sobre la jurisprudencia francesa, ha dictaminado que el error de que habla la Ley de matrimonio civil se refiere solamente a la identidad física del otro contrayente; y en todas las sentencias que ha dictado sobre esta materia, pero sin dar mayores razones que su palabra de autoridad". 
para revelar a la sociedad la amplitud y riqueza del contenido incluido en una norma, labor, por cierto, de no fácil realización, más inherente y distintiva de la función jurisdiccional.

Si dicha función no es competentemente ejercida, entonces, el derecho vería coartada una de sus mayores posibilidades de desarrollo, corriéndose el riesgo de transformarse la regulación del legislador en letra muerte, situación que, precisamente, ocurrió con el precepto que estamos analizando, el que quedó relegado a un objeto de interés sólo científico, alejado de la preocupación de la comunidad, y como consecuencia de lo anterior, fuera de las tres sentencias que hemos señalado en el presente trabajo, excluido de las discusiones propias del foro judicial ${ }^{61}$. En pocas palabras: la ausencia de una regulación explícita de determinada figura jurídica no es factor decisivo para poder arribar a la conclusión de que ella no es recibida por el ordenamiento jurídico de que se trate.

Tengamos presente, también, una segunda consideración: insistimos, es cierto que en norma alguna de la Ley de matrimonio civil de 1884 se efectúa la más mínima referencia explícita al error en las cualidades, pero, al mismo tiempo, su procedencia no es descartada en el texto de la mencionada regulación. Por lo demás, la historia permite acreditar que no sería primera vez que una institución no disciplinada en forma expresa en la ley, más tampoco excluida en los mismos términos, puede ser aceptada tanto por la doctrina como por la jurisprudencia. Sólo por indicar un ejemplo, conocido es que así sucedió en nuestro país con la posibilidad de admitir la indemnización de perjuicios, en sede contractual, en virtud del daño moral sufrido, no obstante el tenor literal del artículo 1556 CC. ${ }^{62}$.Por todo lo indicado precedentemen-

${ }^{61}$ El panorama cambió con la entrada en vigencia de la Ley $\mathrm{N}^{\circ} 19.947$, puesto que se regula expresamente, en el $\mathrm{N}^{\circ} 2$ del artículo 8 , el error en las cualidades personales del otro contrayente. Conocemos solo una sentencia publicada que se ha pronunciado sobre dicha causal de falta de un libre y espontáneo consentimiento matrimonial: la sentencia de la Corte de Apelaciones de Rancagua, en fallo de fecha 1 de junio de 2007, conociendo en consulta el fallo de primera instancia, revoca la sentencia de fecha 6 de marzo de 2007. La cualidad personal alega era la diversidad de credos religiosos. Así, mientras el demandante era católico, la demanda profesaba la fe evangélica. En virtud de lo anterior, no pudo celebrarse matrimonio religioso en conformidad al rito católico, y la demandada se burlaba de los "ídolos católicos". El Tribunal de segunda instancia rechazó la procedencia de la nulidad matrimonial, puesto que la cualidad alegada no era objetivamente relevante para determinar el consentimiento, a diferencia de la impotencia coeundi (en Legal Publishing Chile $\mathrm{N}^{\circ}$ 36465, disponible en: http:// productos.legalpublishing.cl/NXT/publishing.dll? $\mathrm{f}=$ templates $\& \mathrm{fn}=\mathrm{JOLLOL} / \mathrm{de}-$ fault.htm\&3.0\&Tit=A_Juridica/CL_JOL01/CL_JOLL1C\&vid=LNChile:65\&dta $\mathrm{id}=1333576,22-07-2009$.

${ }^{62}$ Basándose en el contenido del citado art., nuestra jurisprudencia rechazaba resarcir el daño moral en el ámbito contractual, dado que, el daño emergente y el lu- 
te, no compartimos este primer argumento esgrimido por la jurisprudencia de los tribunales nacionales para limitar la aplicación del $\mathrm{N}^{\circ} 1$ del artículo 33 de la Ley de matrimonio civil de 1884 únicamente al yerro que incide en la corporeidad del otro contrayente.

2. En aplicación del elemento gramatical de interpretación de la ley, es claro el sentido de la norma al prescribir "error en la persona", expresión referida al error en la corporeidad del otro contrayente.

Es nítido el sentido de la norma al prescribir "error en la persona”, expresión que, desde luego, está referida al error en la corporeidad del otro contrayente, pero no excluye la admisión de otras especies de errores en la persona. En este punto, correcto es mencionar que el elemento gramatical de interpretación de la ley no es el único que debe aplicarse en la hermenéutica legal, pues también, en la medida que ello sea pertinente, el intérprete podrá echar mano a los restantes elementos de interpretación. En este sentido, entendemos que una interpretación lógica de la norma debería haber dirigido al intérprete judicial al acogimiento del error en la persona civil o social y del error en las cualidades. El elemento lógico recibe aplicación, en conformidad a lo prescrito en el inciso $1^{\circ}$ del artículo 19 CC., cuando existen en una ley pasajes obscuros, para la dilucidación de éstos, puede recurrirse a su intención o espíritu. Esta idea se ve reafirmada por la norma establecida en el artículo 22 del mismo cuerpo legal, al señalarse que el contexto de una ley permite ilustrar el sentido de sus partes, de forma tal de que exista la debida correspondencia y armonía.

En este contexto, además, debemos citar el artículo 35 de la Ley de matrimonio civil de 1884, en cuya virtud, la acción de nulidad de matrimonio era imprescriptible, pero no se trataba de una regla absoluta, dado que, reconocía excepciones, entre éstas, el $\mathrm{N}^{\circ} 1$ del artículo 33. Esta norma estableció que, si la acción de nulidad se fundaba en el error en la identidad del otro contrayente, el plazo de prescripción era de un año contado desde la desaparición del hecho que lo origina. No vemos inconveniente en reproducir el argumento que para el derecho francés se sostuvo ${ }^{63}$, esto es,

cro cesante son propios del daño patrimonial y, claro resulta que, el daño moral no es ni lo uno ni lo otro. Lo anterior se retrucó esgrimiendo que, precisamente, aunque la norma no señalase expresamente que se indemniza el daño moral, tampoco lo excluye. Además, se hizo ver que una interpretación restrictiva era contraria a la justicia. Véase: Domínguez, Carmen, El daño moral (Santiago de Chile, Editorial Jurídica de Chile, 2000), II, pp. 350-366.

${ }^{63}$ Ripert, Georges - Boulanger, Jean, Tratado de derecho civil según el tratado de Planiol (trad. García Daireaux, Delia, Buenos Aires, La Ley, 1988), II,1, p. 309. A favor de no restringir el error en la persona sólo al yerro en la corporeidad se pronunció Tou- 
en consideración a la especie de error supuestamente admitido ¿por qué el legislador ha optado por un prolongado plazo de prescripción?, es decir, no se entiende que para un error que recae en la propia persona física se consagre un año completo (el doble del plazo fijado en el Code) para la presentación de la correspondiente demanda. Dada la particular naturaleza del error que aceptó nuestra jurisprudencia, de suma dificultad resultar comprender que hubiese sido necesario un plazo de prescripción de un año. La extensión de

lllier, quien señaló que el error sobre la familia de uno de los contrayentes no constituía vicio del consentimiento, salvo que redundase en un error en la persona; Toullier, C.B.M., Le Drot civil français (continué et complété par Duvergier, 6a edición, Paris, J.B. Cotillon, 1900), I, pp. 312-313. Véase, además: Demolombe, Charles, Traité du mariage et de la séparation de corps (10 edición, Paris, Auguste Durand - L. Hachette et $\mathrm{C}^{\mathrm{ie},}$ 1860), I, p. 411; Josserand, Louis, Derecho civil (trad. Cunchillos y Manterola, Santiago - Buenos Aires, Ediciones Jurídicas Europa-América, Bosch, 1950), I,2; Mazeaud, Henri - Mazeaud, León - Mazeaud Jean, Lecciones de derecho civil. La familia, Constitución de la familia (trad. Alcalá Zamora y Castillo, Luis, Buenos Aires, Ediciones Jurídicas Europa-América, 1976), III, pp. 48-49; y CARbonnier, Jean, Derecho civil (trad. Zorrilla Ruiz, Manuel, Barcelona, Bosch, 1961), I,2, pp. 44-45. Partidario del poder dirimente sólo del error en la identidad física fue Portalis, quien sostuvo que tal yerro era uno de los "impedimentos naturales, porque excluyen la idea de un verdadero consentimiento", PORTALIS, Jean-Etienne-Marie, Discurso preliminar al Código Civil francés (introducción y trad. de Cremades I. y Gutiérrez-Masson, L., Madrid, Civitas, 1997), pp. 59-60. El principal exponente de este sector es PothiER, R.-J., cit. (n. 41), pp. 132-135, quien distinguía entre error en la persona y error acerca de la calidad de la misma. Respecto al primero, consideraba que excluía el consentimiento, lo que justificaba la nulidad del matrimonio, ya que lo esencial era que un hombre y una mujer se quisiesen casar, lo que no ocurría si la mujer con la que se ha casado un hombre era diversa, en términos físicos, de lo que se creía. Con relación al error en la cualidad de la persona, en su opinión, ocurría todo lo contrario, ya que no era de la esencia que la mujer tenga las cualidades esperadas por el hombre, era suficiente con que no se errase en la identidad física. Es decir, para Pothier el error en las cualidades no tenía la entidad necesaria para viciar el consentimiento, ya que la consideración sobre la presencia o ausencia de determinadas cualidades no se comprendía dentro de la esencia del matrimonio, esta clase de error no destruía el consentimiento, se trataba de un arrepentimiento, pero la naturaleza indisoluble del contrato no admitía retractación ni rescisión. Tampoco otorgaba poder relevante al error en las calidades en el evento en que haya sido inducido por dolo. De similar opinión fue Laurent, F., Principes de Droit civil ( $3^{\text {a }}$ edición, Bruxelles, Bruilant-Christophe \& C Ce, Libraires Éditeurs, 1840), p. 380: "es una doctrina deplorable aquella que abdica ante los hechos y que reduce el derecho a lo arbitrario del juez ¿Acaso para consagrar la omnipotencia de los magistrados han formulado los autores del Código Civil todo un capítulo sobre las demandas de nulidad del matrimonio? Diciendo que el matrimonio es nulo cuando hay error en la persona ¿han querido decir que los tribunales pudiesen anular el matrimonio fundándose en el carácter personal del esposo?". Véase también: Salinas Araneda, Carlos, cit. (n. 1), p. 371. 
dicho término, más bien resulta inteligible si se reconoce que el plazo era aplicable a otros supuestos de error en la persona, los que, eventualmente, necesitarían del transcurso de un mayor período de tiempo para poder ser descubierta la falsa representación de la realidad ${ }^{64}$.

Lo anteriormente expuesto se ve reforzado por la siguiente consideración: el plazo de un año no se contaba desde la celebración del matrimonio, sino "desde que haya desaparecido el hecho que los origina". Para aprobar el criterio jurisprudencial que se impuso, habría que consentir que sería probable que, prácticamente, durante un año contado desde el descubrimiento de la verdad, se conviviese con quien, en definitiva, no resultó ser la persona elegida por el perjudicado por el error. Y reiteremos que el yerro se produce en razón de la falta de identidad física del actual cónyuge con la persona deseada como tal. Por estas reflexiones, parece ser más lógico concluir que el plazo prescrito en la antigua ley, debía aplicarse a errores que incidían en la persona social o civil del otro contrayente y en sus cualidades.

Valiosa hubiese sido la resolución judicial que hubiere aceptado estas clases de error en la persona, pero una sentencia como la recientemente indicada, o bien nunca fue dictada o si un juez de primera instancia la pronunció, como sucedió en dos oportunidades, según hemos analizado, los tribunales superiores de justicia se encargaron de truncar la ampliación de la noción de error en la persona en el matrimonio con efecto dirimente del consentimiento.

Sabemos que fácil resulta reprochar lo establecido por nuestros tribunales, pero la dictación de una, por denominarla de alguna manera, "ideal resolución jurisdiccional”, comprensiva de todos los errores relevantes en la persona, debió enfrentarse a la poderosa influencia ejercida en nuestro sistema jurídico por la Escuela de la Exégesis. Estas últimas líneas no representan un intento de justificar lo que hoy podríamos considerar como errónea aplicación del derecho, sino de poner las cosas en una justa perspectiva. En concreto, de acuerdo a las concepciones en aquella época imperantes, se entendió que el sentido de la ley viene a ser el sentido gramatical de la misma, y para acceder a éste, debían explicarse las palabras de la ley mediante otras palabras ${ }^{65}$. En

\footnotetext{
${ }^{64}$ Con respecto a ciertas enfermedades que pueden constituir una cualidad relevante para efectos del consentimiento matrimonial, tengamos en mente que en el caso del síndrome del Sida, y en otras enfermedades (sífilis, "mal de chagas", algunos tipos de cáncer y ciertos tumores, etc.), la etapa en que la enfermedad no presenta síntomas puede comprender un período considerable de tiempo, años inclusive, de forma tal que es posible que el descubrimiento del dolo origen de una especie de error del que se fue víctima sólo acontezca después de transcurridos varios años desde la celebración del matrimonio.

${ }^{65}$ Quintana Bravo, Fernando, Interpretación y argumentación jurídica (Santiago de Chile, Editorial Jurídica de Chile, 2006), p. 213.
} 
este sentido, el recurso a las definiciones del diccionario de la Real Academia Española de la lengua podría entenderse como criterio decisivo para concluir que la norma nacional, al agregar el término "identidad", a diferencia del Código Napoleón, aludiría al otro cónyuge corporalmente considerado. En este sentido, siguiendo a Guzmán Brito ${ }^{66}$, es posible que la interpretación literal de un precepto legal, en vez de guardar armonía con el sentido de la ley, esté en contradicción con éste, y creemos que ello ha ocurrido en la interpretación jurisprudencial del $\mathrm{N}^{\circ} 1$ del artículo 33 de la Ley de matrimonio civil de 1884 .

No pretendemos mediante estos razonamientos esquivar la clara disposición del inciso $1^{\circ}$ del artículo 19 CC., al prescribir que si existe claridad en el sentido de la ley, no puede el intérprete desentenderse de su tenor literal "a pretexto de consultar su intención o espiritu". La citada norma no establece una prohibición relativa al recurso al espíritu de la ley, todo lo contrario, lo posibilita al regular la situación en que ello es procedente: cuando el sentido de la ley no es claro, por lo tanto, si tal sentido es nítido, no corresponde acudir al espíritu de la ley. Entonces, podemos preguntarnos, ¿era claro el sentido del $\mathrm{N}^{\circ} 1$ del artículo 33 de la primera Ley de matrimonio civil de nuestro país?, opinamos que la respuesta debe ser negativa. En efecto, no existía la suficiente claridad en la norma de forma tal que quedase vedado el acudir al espíritu de ella. Afirmamos lo anterior ya que resulta evidente la ausencia de un consenso sobre los tipos de errores incluidos en el precepto, y la discusión como hemos visto no se reduce sólo a Chile, alcanzando mayores alturas en otras naciones, como en Italia ${ }^{67}$ y el ya aludido caso francés.

${ }^{66}$ Afirma Guzmán Brito, Alejandro, Las reglas del "Código Civil" de Chile sobre interpretación de las leyes (Santiago de Chile, LexisNexis, 2007), pp. 75-76, que: "la distinción verba-sententia, para emplear la terminología romana más usual, es propiamente una distinción entre el sentido de las palabras de la ley, por un lado, y el sentido de la ley, por otro, en función de una comparación que puede resolverse en una coincidencia, si el sentido de las palabras, o tenor literal, porta congruentemente el sentido de la ley y éste se manifiesta exactamente a través de aquél; o bien, en una verdadera disconformidad, cuando uno es el sentido de las palabras, o tenor literal, y otro el sentido de la ley".

${ }^{67}$ El Codice Civile de 1865 reguló el error en el matrimonio en el artículo 105, aceptando el error en la persona del otro contrayente. El mencionado precepto establecía lo siguiente: "El matrimonio puede ser impugnado por aquel de los esposos cuyo consentimiento no haya sido libre. Cuando hubiese error en la persona, la acción de nulidad puede ser promovida por aquel de los esposos que fue inducido al error"; véase: BORSARI, Luigi, Commentario del Codice Civile italiano (Torino, Società Unione Tipografico-Editrice Torinense, 1871), I, pp. 401-403. Revísese, además: SAVErio BiANCHI, Francesco, Corso di Codice Civile italiano. Della parentela, dell affinità e del matrimonio (Torino, Unione Tipografico-Editrice Torinense, 1893), V,1, pp. 248-260. Lo anterior obedeció al claro influjo ejercido por el artículo 180 del Código galo. También en este ordenamiento se discutió si la norma se refería a la identidad física, a la personalidad civil o al error en una cualidad esencial. Lo mismo sucedió en la jurisprudencia; véase: SALI- 
Similar polémica no surgió en ordenamientos, como el caso del derecho matrimonial alemán, en los que existía una expresa recepción legislativa del error en las cualidades ${ }^{68}$.

\section{El espiritu democrático de nuestra legislación impide aceptar el error en} las cualidades, ya que aquélla tiende a la nivelación social.

Otro argumento esgrimido por la jurisprudencia nacional para rechazar el yerro sobre las cualidades fue que el espíritu democrático de nuestra legislación lo impediría, puesto que, aquélla tiende a la nivelación social. Desde luego, es loable que nuestros tribunales, en la resolución de los conflictos sometidos a su resolución, consideren como un factor preponderante el deseo de igualdad social que debe inspirar a toda legislación, pero esta adecuada aspiración, en la especie, puede conducir a una confusión. Pensemos en lo siguiente: la eventual admisión, vía jurisprudencial, del error en las cualidades no hubiese debido significar, necesariamente, una desigualdad social. Ello pudiese haber tenido lugar sólo si la interpretación de la figura no hubiese logrado una adecuada intelección de la misma. Así, por ejemplo, si se hubiera entendido que errores tales como los recaídos en la fortuna o en el patrimonio, tuviesen la entidad necesaria para fundamentar una declaración de nulidad matrimonial.

El criterio para evitar caer en este confusionismo es no perder de vista que se está hablando de un tipo de error de hecho que recae "en la persona" del otro contrayente, y no de yerros sobre aspectos que no se incardinan

Nas Araneda, Carlos (cit. n. 2), pp. 392-393. Un resumen de la discusión se encuentra en Stolfi, Nicola, Diritto civile. Diritto di famiglia (Torino, Unione TipograficoEditrice Torinense, 1921), V, pp. 93-97. Véase, además: Butera, Antonio, Il Codice Civile italiano. Libro primo (Torino, Unione Tipografico-Editrice Torinese, 1939), pp. 198-200; y Cicu, Antonio, El derecho de familia (trad. Sentís Melendo, Santiago, Buenos Aires, Ediar, 1947), p. 351. La discusión quedó resuelta por el Código Civil de 1942, texto en cuyo artículo 122 se aceptó el error en la identidad física y el error en las cualidades, siempre que se resolviese en un error en la identidad de la persona; véanse: Capizzano, Ezio, L'errore sulle qualità dell altro coninge come causa di nullità del matrimonio, en Rivista del Diritto Matrimoniale e dello Stato delle Persone (1960), p. 629; y Barbero, Domenico, Sistema del derecho privado. derechos de la personalidad. derecho de familia-derechos reales (trad. Sentís Melendo, Santiago, Buenos Aires, Ediciones Jurídicas Europa-América, 1967), II, p. 60.

${ }^{68}$ En Alemania, el parágrafo 1333 del Código Civil (BGB) aceptó el valor dirimente del error en las cualidades. Se afirmó que: "Sólo tiene efecto un error sobre las cualidades personales del otro cónyuge, no sobre las propias, como la ignorancia de la propia esterilidad o enfermedad. Tampoco sirve un error sobre las condiciones de los familiares del otro cónyuge": EnNeccerus, Ludwig - Kipp, Theodor - Wolf, Martin, Tratado de derecho civil, derecho de familia ( $2^{\mathrm{a}}$ edición, trad. Pérez González, Blas y Castán Tobeñas, José, Barcelona, Bosch, 1953), IV,1, p. 152. 
en la noción de "persona". Es decir, no existe inconveniente en, por una parte, excluir errores basados en cualidades netamente económicas, que no guardan relación con lo que debe entenderse comprendido en la expresión "persona" y, por otra parte, sostener la admisibilidad del error en las cualidades $^{69}$. Para lograr lo anterior, debe distinguirse el tipo de cualidades que tienen la potencialidad, en atención a su entidad, de ocasionar un error relevante para efectos del consentimiento matrimonial. De este modo, errores que inciden en aspectos patrimoniales, no guardan relación o, si se quiere, son accesorios a la persona del otro contrayente. En definitiva, esta clase de errores no se radican en la persona del otro: ni en el aspecto físico, ni en las cualidades que determinan su lugar en la sociedad ni en otro tipo de caracteres que una debida consideración de la naturaleza y/o los fines del matrimonio lleve a considerar como relevantes si lo que se persigue es proteger un consentimiento libre y espontáneo, por lo tanto, a su respecto, no procede el error en la identidad física, el error en la persona civil o social ni el error en las cualidades.

La ventaja de esta interpretación es doble: en primer lugar, evita odiosas desigualdades sociales y, en segundo término, contribuye a una más amplia tutela del libre y espontáneo consentimiento matrimonial. Con relación a lo primero, se elimina la posibilidad que consideraciones relativas al mayor o menor activo del patrimonio del otro contrayente puedan considerarse como motivo suficiente para declarar la nulidad, con lo que se cumple con el interés de los tribunales en orden a no violar la igualdad ante la ley, no esta-

\footnotetext{
${ }^{69}$ Se ha sostenido que "la irrelevancia invalidatoria del error de fortuna parece lógica, porque la solución contraria no sería conforme a la consideración del matrimonio como una plena comunidad de vida corporal y espiritual entre los cónyuges, y supondría una injustificada patrimonialización de la relación jurídico- matrimonial": Vivó de Undabarren y otros, Derecho matrimonial comparado (Valencia, Tirant lo Blanch, 2005), p. 114. Señala Salinas que el tema del error en el matrimonio empezó a introducirse en la práctica de la Iglesia en el siglo IX, en razón de matrimonios entre nobles celebrados mediante procurador, en los que no era inusual la sustitución de uno de los novios, y que fue Graciano el primero en analizarlo en forma expresa. Graciano distinguió entre error en la persona, error de fortuna, error en las cualidades y error en la condición servil. De éstos, el error de fortuna y el error en las cualidades carecían de poder irritante: Decretum Gratiani (Parisiis, 1601), C. 29, q. 1 y 2. Véase además: Navarrete, Urbano, Derecho matrimonial canónico, evolución a la luz del Concilio Vaticano II (Madrid, Biblioteca de Autores Cristianos, 2007), pp. 684-685; y SALINAS ARANeda, Carlos, El error en la persona del otro cónyuge en la historia del derecho canónico, en Revista de Estudios Histórico-Jurídicos, 20 (1998), pp. 223-225. Para Llamazares Fernández, Dionisio, El sistema matrimonial español (Madrid, Servicio de Publicaciones de la Facultad Derecho, Universidad Complutense, 1995), p. 18, el objeto del matrimonio está dado por la persona del contrayente y por sus cualidades personales, no por su mayor o menor fortuna,
} 
bleciendo diferencias enojosas basadas en la fortuna de las personas. Respecto a lo segundo, se logra una más efectiva protección de la voluntad, al permitir que errores en la persona, de indudable mayor ocurrencia que el recaído en la identidad física, tengan poder dirimente de la voluntad matrimonial.

\section{Los errores diversos al yerro sobre la identidad fisica no tienen la entidad} suficiente para viciar el consentimiento.

Además, los tribunales basaban sus resoluciones en atención a que los errores diversos al yerro sobre la identidad física del otro contrayente no tendrían la entidad suficiente para viciar el consentimiento. Este argumento también merece nuestras observaciones. Pensemos en lo siguiente: ¿se opone a un libre y espontáneo consentimiento matrimonial un error diverso al yerro in corpore? Respondemos que sí: entendemos que cualidades tales como la infertilidad, enfermedades particularmente contagiosas, determinadas creencias religiosas o morales, etc., atentan en contra de lo que protegía el artículo 33 de la Ley de matrimonio civil de 1884.

Considérese que lo buscado por el $\mathrm{N}^{\circ} 1$ del artículo 33 era la protección del consentimiento matrimonial, objetivo no logrado con una interpretación restrictiva de la norma, por lo tanto, una lógica y teleológica interpretación del texto del aludido precepto debió haber conducido a la inclusión de errores distintos al recaído en la identidad física. Efectivamente, no parece ser lógico el interpretar una norma de forma tal de dejar desguarnecido el fin pretendido, que en este caso es proteger el consentimiento de los contrayentes de errores de entidad, como pueden serlos los que inciden en la persona social y en otras cualidades. No debió desconocerse que ciertos yerros en determinadas cualidades pueden estar revestidos de la misma trascendencia que el referente a la identidad física y, si lo que se busca es conceder una custodia íntegra al consentimiento matrimonial, entonces, debieron haber sido aceptados, pensemos, por ejemplo, en la impotencia coeundi $i^{70}$, en el embarazo ab alio y en la drogadicción ${ }^{71}$.

${ }^{70}$ En la LMC. de 1884, la impotencia se regulaba como un impedimento dirimente absoluto, en el art. $4 \mathrm{n}^{\circ}$ 3: "No podrán contraer matrimonio: los que sufrieren de impotencia perpetua e incurable". Véase: Troncoso LARRONDE, Hernán, Algunos aspectos de la nulidad de matrimonio, en Revista de Derecho, 219-220 (Universidad de Concepción, 2006), pp. 205-206.

${ }^{71}$ Debe tratarse de una dependencia que perturbe gravemente el consorcio conyugal. Tan arraigado estaba el vicio en un hombre que el día de su boda, no pudiendo resistir, se inyectó heroína. La cualidad sobre la que se erró existía en forma previa al matrimonio; la drogadicción era para el demandado un grave problema desde los dieciséis años, c. Riera, J., sentencia del Tribunal Eclesiástico del Arzobispado de Barcelona, de 1 de abril de 1989, en Revista Española de Derecho Canónico, 
Ahora bien, el problema es que la función de determinar cuáles habrían sido esas cualidades debió haberse ejercido, principalmente, por los propios tribunales, caso a caso, considerando toda cualidad que tuviese el potencial de afectar una voluntad exenta de ignorancias y equivocaciones. Recordemos que una buena parte de la doctrina chilena admitía, a lo menos, el valor irritante del consentimiento matrimonial del error en la persona social, según hemos indicado en su momento. Pero, lamentablemente, la jurisprudencia ni siquiera aceptó dicha postura intermedia. Pensamos que un factor clave para tal decisión fue la preocupación por la estabilidad del matrimonio. Y se trata de un comprensible interés, pero con esta interpretación se pueden lograr resultados inicuos, y no se respeta en su justa medida la voluntad libre y espontánea del contrayente, existe, en consecuencia, una colisión de intereses, de ahí que surja la pregunta: ¿cómo conciliamos el interés social existente en la preservación del vínculo matrimonial con las exigencias de la justicia que reclaman la nulidad de otros errores en la persona? Desde luego, no es posible cumplir este objetivo negando lisa y llanamente la admisión de todo tipo de error en la persona diferente del error en la identidad física, pero tampoco se consigue dicha meta aceptando indiscriminadamente los otros yerros. Un modelo para poder lograr una solución satisfactoria era propuesto tanto por el derecho canónico como por el derecho comparado: se aceptaba el error en las cualidades, pero en forma excepcional y cumpliendo ciertos requisitos, de lo cual puede concluirse que debía tratarse de cualidades de tal relevancia que afectasen profundamente la convivencia matrimonial y que, si hubiesen sido conocidas, la víctima del error no hubiese prestado su consentimiento.

No se trata de romper con la irrelevancia del error en los motivos, sino de admitir que, en ciertos supuestos, un error en una cualidad (social o de otra naturaleza) puede ser tan determinante, para efectos del consentimiento matrimonial, como un error en la identidad física; claro está que la aceptación del error en las cualidades debe estar limitada por determinados requisitos. De ahí la importancia de la jurisprudencia en establecer supuestos y criterios de apreciación de cualidades con la entidad suficiente para justificar la disolución de un matrimonio por vía de la nulidad. Lamentablemente, la jurisprudencia se mantuvo apegada a una interpretación restrictiva del $\mathrm{N}^{\circ} 1$ del artículo 33. En otras palabras, en el conflicto entre la preservación del matrimonio y una voluntad realmente libre y espontánea, salía gananciosa, claramente, la

127 (1989), p. 733. Véase, además: Martínez Blanco, Antonio, Reflexiones sobre la incidencia de la drogadicción en el consentimiento matrimonial canónico según la jurisprudencia de la Rota Romana (1986-1994), en CASTÁn VÁsQueZ, José María y otros (coordinadores), "Hominum causa omne ius constitutum est". Escritos sobre el matrimonio en homenaje al Prof. Dr. José Maria Díaz Moreno, S.J. (Madrid, Universidad Pontificia de Comillas, 2000), p. 591. 
primera. Entendemos que esta opción, fácilmente criticable bajo los criterios actuales dominantes, es entendible dado el contexto existente, especialmente en las primeras décadas siguientes a la promulgación de la ley, época en que la conservación del vínculo matrimonial era considerada, prácticamente en forma unánime, como ligada necesariamente al bienestar de la sociedad; por dicha razón, toda institución que pudiese ampliar las posibilidades de obtener la disolución de un matrimonio era mirada con preocupación.

\section{La noción de persona del artículo 55 del Código Civil se refiere a todo} nacido de mujer con independencia de sus cualidades, accidentes o atributos.

Asimismo, para fundamentar el persistente rechazo a la ampliación del ámbito de aplicación del error en el matrimonio, los tribunales chilenos manifestaron que la noción de "persona" del artículo 55 CC. está referida a todo nacido de mujer, con independencia de sus cualidades, accidentes o atributos. No es posible cuestionar lo anterior. Indisputable es que todo nacido de mujer, con independencia de su edad, sexo, estirpe o condición es persona, y por lo tanto, sujeto de derecho. El contenido de la definición de "persona" apunta a dejar claramente establecido el repudio a la antigua legislación española que comprendía que no eran personas aquellos seres que no presentaban los signos propios de la humanidad, es decir, el criterio decisivo era la apariencia externa de un sujeto ${ }^{72}$. Pero el análisis no debe finalizar aquí, ya que debe agregarse una segunda consideración: la admisión del error en la persona social o civil y del error en las cualidades no significaba contradecir la definición legal de persona establecida en el Código Civil. Ahora bien, si bien es cierto que, a diferencia del Código Civil de Francia de 1804, el legislador nacional innovó al introducir en el $\mathrm{N}^{\circ} 1$ del artículo 33 la expresión "identidad", ello no es motivo suficiente para limitar su aplicación sólo al error en la identidad física de la persona. De hecho, la propia definición de "identidad", nos enseña que ella apunta a la cualidad de ser idéntica una cosa con otra, y la voz "idéntica", por su parte, implica lo que en sustancia o realidad es lo mismo que otra cosa. Tomando en cuenta lo anterior, sostenemos que no puede afirmarse que existe identidad en la persona si aquel con quien se ha contraído matrimonio, no posee cualidades particularmente deseadas o presenta caracteres repudiables, las que se

${ }^{72}$ La legislación española de la que se quería desmarcar Bello era la Ley $5^{\mathrm{a}}$, título $23^{\circ}$ de la Partida 4a que establecía: "No deben ser contados por fijos, los que nacen de mujer é non son figurados como homes, asi como si tubiesen cabeza u otros miembros de bestia; mas si la criatura que nace, a figura de home, maguer haya miembros sobrejanos, o menguados, no le empece para heredar". Véase,: Lyon Puelma, Alberto, Personas naturales ( $3^{\text {a }}$ edición, Santiago de Chile, Ediciones Pontifica Universidad Católica de Chile, 2007), pp. 35-36. 
consideraban presentes o ausentes, según corresponda, por el que ha caído en error. Por supuesto, dichas cualidades deben haber tenido relevancia de primer orden en la manifestación de la voluntad dirigida a la elección del otro como futuro cónyuge.

Puede apreciarse una coherencia en los fundamentos que apoyan las decisiones jurisprudenciales. Nuestros tribunales, aplicando el elemento gramatical de interpretación han establecido que el $\mathrm{N}^{\circ} 1$ del artículo 33 se limita a la identidad física, y no se refiere a las cualidades, aunque se trate de las señaladas en el artículo 55 a propósito de la definición de persona (edad, sexo, estirpe, condición), ni siquiera a las que identifican socialmente a un sujeto. En concordancia con el criterio establecido por la jurisprudencia nacional, bastaba para descartar el error el hecho que estuviese presente en la ceremonia el otro contrayente, aunque se ignorase que fuese estéril, sifilítico o un ebrio permanente. La fórmula empleada por el legislador de 1884, "error en la identidad de la persona", no puede servir de base para excluir la admisibilidad de otros errores. La jurisprudencia pasa por alto que la identidad de una persona no se circunscribe en forma única a ésta como un ser físicamente determinado, al contrario, es una noción más amplia, comprensiva, desde luego, de la persona física, pero en la que se encuentra incluida, además, el error en la persona social o civil y el error en las cualidades.

\section{SíNTESIS}

Por todas estas razones, y desde la cómoda perspectiva que nos ofrece el actual nivel de desarrollo alcanzado por el derecho de familia en nuestro país, señalamos que la adecuada interpretación del $\mathrm{N}^{\circ} 1$ del artículo 33 de la Ley de matrimonio civil de 1884 fue la propuesta por, entre otros, Meza Barros. En consecuencia, la mencionada norma protegía la voluntad de los contrayentes de los errores que incidían en la identidad física, en la persona civil o social, y en las cualidades del otro contrayente.

No obstante lo expresado por un relevante sector de la doctrina, el que incluye a varios de los autores más lúcidos del derecho civil patrio, es evidente que para la jurisprudencia no se presentó duda alguna: en los pocos fallos en que se alegó el error como vicio de la voluntad matrimonial, en definitiva, se concluyó que estaba referido sólo al error en la identidad física. En este contexto, era obvio que toda petición fundada en un error distinto al error en la identidad física no tenía ninguna esperanza de ser acogida en los tribunales. La jurisprudencia chilena negó poder irritante a cualidades como el nombre, clase de filiación, parentesco, ausencia de las condiciones orgánicas y espirituales necesarias para poder permanecer sin grave detrimento de la salud y bienestar en el país, capacidad y estado civil. 
En razón de lo expuesto, criticamos la solución adoptada por la jurisprudencia chilena, en exceso apegada a una interpretación literal, al circunscribir el $\mathrm{N}^{\circ} 1$ del artículo 33, única y exclusivamente, al difícil supuesto de error en la identidad física. En este escenario, la norma, prácticamente, no tuvo esperanza de pasar a resultar aplicable, transformándose en letra muerta. Como hemos adelantado, este es uno de los factores que pueden haber contribuido al episodio de las nulidades matrimoniales fraudulentas logradas al amparo de una supuesta incompetencia del Oficial de Registro Civil ${ }^{73}$. En virtud de lo señalado, ¿puede afirmarse, en consecuencia, que el consentimiento matrimonial no era debidamente tutelado a raíz de la no inclusión del error en la persona social y del error en las cualidades en el $\mathrm{N}^{\circ} 1$ del artículo 33? Pensamos que la respuesta es afirmativa, ya que, de las tres especies de error en la persona, sólo se aceptaba por la jurisprudencia una, y ésta era de difícil o casi imposible producción.

En este estado de cosas, puede concluirse que la legislación matrimonial chilena, que se nutrió de los aportes provenientes del ámbito canónico, en consideración a la interpretación que se dio al $\mathrm{N}^{\circ} 1$ del artículo 33 de la Ley de matrimonio civil de 1884, quedó atrasada en comparación a su modelo canónico. Esta era la situación hasta antes de la entrada en vigencia el año 2004 de la Ley No 19.947, nueva Ley de matrimonio civil. Con esta nueva ley se reguló explícitamente en el $\mathrm{N}^{\circ} 2$ del artículo 8 el error en las cualidades personales, y se incluyen cualidades de diverso tipo, inclusas las sociales, por lo que dicha norma sanciona el error en la persona social, siempre que las cualidades de que se trate sean determinantes para el consentimiento matrimonial en atención a la naturaleza o los fines del matrimonio ${ }^{74}$.

${ }^{73}$ No queremos establecer que se trate de la única causa de las mencionadas nulidades, desde luego, debemos admitir que al no poder operar las restantes causales de nulidad y al no existir un divorcio vincular, se arribó al descrito estado de cosas.

${ }^{74} \mathrm{Al}$ mantenerse el texto del $\mathrm{n}^{\circ} 1$ del art. 33 de la LMC de 1884 , en el sentido de no precisar el No 1 del artículo 8 de la NLMC a que "identidad" del otro contrayente se refiere, CoRral TALCIANi, Hernán, El régimen de los requisitos del matrimonio y de la nulidad en la nueva Ley de matrimonio civil, en Corral TAlCiani Hernán - AsSimakópulus Figueroa, Anastasía (editores), Cuadernos de extensión jurídica 11: Matrimonio civil y divorcio. Análisis critico y criterios para la aplicación de la Ley No 19.947, de 2004 (Santiago de Chile, Universidad de los Andes, 2005), p. 49, ha expresado que se mantiene vigente la duda con relación a si, además del error en la identidad física, se incluye en el $N^{\circ} 1$ del artículo 8 el error en la identidad jurídica, En contra, Domínguez Hidalgo, Carmen, Reformas a la formación y efectos del matrimonio en la Nueva Ley: un apunte general en Seminario "Nueva Ley de matrimonio civil, Ley $N^{o}$ 19.947” (Santiago de Chile, Colegio de Abogados, 2004), p. 9: el № 2 del artículo 8 que admite la relevancia del error en las cualidades suprime la referida discusión, Por nuestra parte, al igual que Domínguez, entendemos que la aludida disputa ha quedado resuelta por la NLMC. En consecuencia, el así denominado "error en la identidad ju- 


\section{BiBLIOGRAFÍA}

Alessandri Rodríguez, Arturo, derecho Civil. Tercer Año. derecho de Familia. De la sucesión por causa de muerte (Santiago de Chile, Pedro Trouvé, 1932).

Alfonso Ma De Ligorio, San, “Theologia moralis” (2a edición, Neapoli, 1755).

Barbero, Domenico, Sistema del derecho privado, derechos de la personalidad.Derecho de familia-derechos reales (trad. Sentís Melendo, Santiago, Buenos Aires, Ediciones Jurídicas Europa-América, 1967).

Borsari, Luigi, Commentario del Codice Civile italiano (Torino, Societá L'unione Tipografico- Editrice, 1871), I.

Butera, Antonio, Il Codice Civile italiano. Libroprimo (Torino, Unione TipograficoEditrice Torinese, 1939).

Capizzano, Ezio, L'errore sulle qualità dell altro coninge come causa di nullità del matrimonio, en Rivista del Diritto Matrimoniale e dello Stato delle Persone (1960).

Carbonnier, Jean, Derecho civil (trad. Zorrilla Ruiz, Manuel, Barcelona, Bosch, 1961), I,2.

Chacón, Jacinto, Esposicion razonada y estudio comparado del Código Civil chileno (Valparaíso, Imprenta del Mercurio, 1868).

Cicu, Antonio, El derecho de familia (trad. Sentís Melendo, Santiago - Buenos Aires, Ediar, 1947).

Claro Solar, Explicaciones de derecho civily comparado ${ }^{2}$ (Santiago de Chile, Editorial Jurídica de Chile, 1992), I,1.

Corral Talciani, Hernán, El régimen de los requisitos del matrimonio y de la nulidad en la nueva Ley de matrimonio civil, en Corral Talciani, Hernán - Assimakópulus Figueroa, Anastasía (editores), Cuadernos de extensión jurídica 11: Matrimonio civil y divorcio. Análisis critico y criterios para la aplicación de la Ley $N^{o}$ 19.947, de 2004 (Santiago de Chile, Universidad de los Andes, 2005).

Decretum Gratiani (Parisiis, 1601).

Demolombe, C. Traitédu mariage et de la séparation de corps (10 a edición, París, Auguste Durand - L. Hachette et $\left.C^{i e}, 1860\right)$, I.

Domínguez, Carmen, El daño moral (Santiago de Chile, Editorial Jurídica de Chile, 2000), I.

Domínguez, Carmen, Reformas a la formación y efectos del matrimonio en la Nueva Ley:

rídica, social o civil”, está comprendido en la regulación que dicha ley efectúa respecto del error en las cualidades. Si en el no 2 del artículo 8 se incluyen no solo las cualidades de índole física, sino también, las de otra naturaleza, como sociales, morales, etc., de ello se sigue que, el error en la identidad civil, como el que recae en el parentesco o en el tipo de filiación, debe sancionarse al tenor de lo prescrito en el no 2 del artículo 8 y no por el $n^{\circ} 1$ de la misma norma. En este último $n^{\circ}$ se sanciona el error en la identidad física y el error redundans. Es decir, y en definitiva, sostenemos que si la cualidad social sobre la que se ha errado viene a individualizar a la persona del otro contrayente, de una manera tan intensa que redunda en la propia identidad de ésta, identificándola, entonces lo adecuado es aplicar el $n^{\circ} 1$ del artículo 8 , pero en atención a que se trata de un error redundans, no porque la identidad social esté incluida per se en la fórmula que dicho número utiliza. 
un apunte general, en Seminario "Nueva Ley de matrimonio civil, Ley No 19.947" (Santiago de Chile, Colegio de Abogados, 2004).

Enneccerus, Ludwig - Kipp, Theodor - Wolf, Martin, Tratado de derecho civil, derecho de familia ( $2^{a}$ edición, trad. Pérez González, Blas y Castán Tobeñas, José, Barcelona, Bosch, 1953).

Fueyo Laneri, Fernando, Derecho Civil. Derecho de Familia (Santiago de Chile, Imp. y Lito. Universo S.A., 1959), VI,1.

Guzmán Brito, Alejandro, Las reglas del “Código Civil” de Chile sobre interpretación de las leyes (Santiago de Chile, LexisNexis, 2007).

Josserand, Louis, Derecho civil (trad. Cunchillos y Manterola, Santiago de Chile, Buenos Aires, Ediciones Jurídicas Europa-América, Bosch, 1950), I,2.

Laurent, F., Principes de Droit civil ( $3^{\mathrm{a}}$ edición, Bruxelles, Bruilant-Christophe $\& \mathrm{C}^{\mathrm{ie}}$, Libraires Éditeurs, 1840).

Llamazares Fernández, Dionisio, Elsistema matrimonial español (Madrid, Servicio publicaciones facultad derecho, Universidad Complutense, 1995).

Lyon Puelma, Alberto, Personas naturales ( $3^{a}$ edición, Santiago de Chile, Ediciones Pontifica Universidad Católica de Chile, 2007).

Martínez Blanco, Antonio, Reflexiones sobre la incidencia de la drogadicción en el consentimiento matrimonial canónico según la jurisprudencia de la Rota Romana (1986-1994), en CASTán VÁsQuez, José María y otros (coordinadores), "Hominum causa omne ius constitutum est”. Escritos sobre el matrimonio en homenaje al Prof. Dr. José Maria Díaz Moreno, S.J. (Madrid, Universidad Pontificia de Comillas, 2000).

Mazeaud, Henri - Mazeaud, León - Mazeaud Jean, Lecciones de derecho civil. La familia, Constitución de la familia (trad. Alcalá Zamora y Castillo, Luis, Buenos Aires, Ediciones Jurídicas Europa-América, 1976), III.

Meza Barros, Ramón, Manual de derecho de familia (2a edición, Santiago de Chile, Editorial Jurídica de Chile, 1989).

Mondaca Miranda, Alexis, Aplicación de un criterio objetivo-subjetivo en la apreciación de la entidad de las cualidades cuya falsa representación puede originar el error disciplinado en el $N^{\circ} 2$ del artículo $8^{\circ}$ de la nueva Ley de matrimonio civil, en Departamento de derecho privado Universidad de Concepción (coordinador), Estudios de derecho civil.Jornadas Nacionales de derecho civil, Concepción, 2009 (Santiago de Chile, Abeledo Perrot LegalPublishing, 2010), VII.

Navarrete, Urbano, Derecho matrimonial canónico, evolución a la luz del Concilio Vaticano II (Madrid, Biblioteca de Autores Cristianos, 2007).

Pinochet EloRza, César, El error en la persona en el contrato de matrimonio (memoria de grado, Universidad de Chile, Santiago de Chile, 1960).

Portalis, Jean-Etienne-Marie, Discurso preliminar al Código Civil francés (introducción y trad. de Cremades I. y Gutiérrez-Masson, L., Madrid, Civitas, 1997).

Pothier, Robert-Joseph, Tratado del contrato de matrimonio (trad. Noguera Mariano y Carles, Francisco, Barcelona, Imprenta y Litografía de J. Roger, 1846).

Quintana Bravo, Fernando, Interpretación y argumentación jurídica (Santiago de Chile, Editorial Jurídica de Chile, 2006).

Ripert, Georges - Boulanger, Jean, Tratado de derecho civilsegún el tratado de Planiol (trad. García Daireaux, Delia, Buenos Aires, La Ley, 1988), II,1.

Rossel SaAvedra, Enrique, Manual de derecho de familia (6a edición, Santiago de Chile, Editorial Jurídica de Chile, 1992). 
Rozas Vial, Fernando - Barros Freire, Jorge, Derecho Civil. Derecho de Familia (Santiago de Chile, Ediciones Albatros Chilena, 1970), I.

Ruano Espina, Lourdes, El error de cualidad, como causal de nulidad matrimonial, en los ordenamientos canónico y civil, en Revista de Derecho Privado, 76 (1992).

SaAvedra, Francisco, Teoría del consentimiento (Santiago de Chile, Editorial Jurídica ConoSur, 1994).

Salinas Araneda, Carlos, El error en el matrimonio (Santiago de Chile, Universidad Central de Chile, 2005), II.

Salinas Araneda, Carlos, El error en la persona del otro cónyuge en la historia del derecho canónico, en Revista de Estudios Histórico-Jurídicos, 20 (1998).

Salinas Araneda, Carlos, El influjo del derecho canónico en el Código Civil de la República de Chile (Valparaíso, Ediciones Universitarias de Valparaíso, 2006).

SÁnCHEZ, Tomás, Disputationum de sancto matrimonii sacramento (Antuerpiae, 1626), II.

Saverio Bianchi, Francesco, Corso di Codice Civile italiano. Della parentela, dell affinità e del matrimonio (Torino, Unione Tipografico-Editrice, 1893), V,1.

Somarriva Undurraga, Manuel, Derecho de familia (Santiago de Chile, Editorial Nascimento, 1963).

Stolfi, Nicola, Diritto civile. Diritto difamiglia (Torino, Unione Tipografico-Editrice Torinense, 1921), V.

TAPIA DE LA TORRE, José, Discusión parlamentaria de la Ley de matrimonio civil chilena (memoria de grado, Pontificia Universidad Católica de Valparaíso, Valparaíso, 1990).

Troncoso Larronde, Hernán, Algunos aspectos de la nulidad de matrimonio, en Revista de Derecho, 219-220 (Universidad de Concepción, 2006).

Toullier, C.B.M., Le Drot civil français (continuéet complétépar Duvergier ( $6^{a}$ edición, París, J.-B. Cotillon, 1900), I.

VARgas Bugueño, Cristián, Los vicios del consentimiento en el derecho canónico y en el matrimonio civil de Chile y de algunos paises latinoamericanos (memoria de grado, Pontificia Universidad Católica de Valparaíso, Valparaíso, 2000).

Velasco Letelier, Eugenio, De la disolución del matrimonio (Santiago de Chile, Editorial Jurídica de Chile, 1973).

Vivó de Undabarrena, Enrique y otros, Derecho matrimonial comparado (Valencia, Tirant lo Blanch, 2005). 
